\title{
Determinantes do Desempenho Econômico das Mesorregiões Oeste Paranaense e Oeste Catarinense entre 1970 e 2000
}

\section{Economic Performance Determinants of the West of Paraná and Santa Catarina States Mesoregions between 1970 and 2000}

\author{
Lucir Reinaldo Alves* \\ Carlos Aguedo Nagel Paiva**
}

Resumo: Este artigo analisa os determinantes do desempenho econômico das mesorregiões Oeste Catarinense e Oeste Paranaense no período 1970-2000, analisando a distribuição das atividades econômicas e as especializações mesorregionais. Essas duas mesorregiões possuíam algumas similaridades em suas estruturas fundiárias, estruturas competitivas e padrões de organização do trabalho em 1970. Além disso, elas apresentaram desempenhos econômicos muito superiores aos apresentados pelo conjunto do Sul do Brasil no período analisado. Utilizou-se como metodologia a aplicação do método estrutural-diferencial. Os resultados apontaram que a explicação desse desempenho superior esteve atrelada às opções produtivas (especializações), no período, de cada mesorregião. Assim, de forma geral, no período 1970-2000, ambas mesorregiões se diversificaram, integraram os três macrossetores, e apresentaram uma indução de economias externas que se refletiu em melhores condições socioeconômicas, em comparação com outras mesorregiões e o próprio Sul do Brasil como um todo.

Palavras-chave: Análise regional. Mesorregiões. Desenvolvimento regional.

Abstract: This article investigates the determinants of economic performance of the mesoregions Oeste Catarinense and Oeste Paranaense in the period of 1970 to 2000, analyzing the distribution of the mesoregions' economic activities and specializations. These two mesoregions hold similarities in their agrarian and competitive structures, as well as in their standards of labor organization in the 1970s. In addition, both mesoregions showed a highly superior economical performance to that presented by the South of Brazil in the analyzed period. The study employed the Shift-Share methodology. The results showed that the productive options (specializations) of each mesoregion explain their differentiated performance in the period. Hence, in the period of 1970 to 2000, both mesoregions diversified and integrated the three macro-sectors, what reflected on better economic conditions in comparison with other mesoregions and with the South of Brazil.

Keywords: Regional analysis. Mesoregions. Regional development.

JEL Classification: O18; R12.

* $\quad$ Economista. Mestre em Desenvolvimento Regional pela Universidade de Santa Cruz do Sul (UNISC). Professor assistente do curso de Ciências Econômicas da Unioeste/Toledo-PR. Pesquisador do Grupo de Pesquisa em Agronegócio e Desenvolvimento Regional (Gepec) e do Grupo Dinâmicas Socioeconômicas Nacionais e Regionais Comparadas (DISENREC).E-mail: lucir_a@hotmail.com

* $\quad$ Economista. Pesquisador da Fundação de Economia e Estatística (FEE). Professor do Programa de Mestrado e Doutorado em Desenvolvimento Regional da Universidade de Santa Cruz do Sul (Unisc). E-mail: carlosanpaiva@gmail.com 


\section{1 lntrodução}

O objetivo deste artigo é analisar os determinantes do desempenho global e setorial das mesorregiões Oeste Catarinense e Oeste Paranaense (Figura 1), no período 1970-2000, analisando a distribuição das atividades econômicas no decorrer desse período e comparando o desempenho dessas duas mesorregiões paranaenses com o Sul do Brasil.

A partir da década de 1950, grandes transformações ocorreram na distribuição das atividades econômicas devido à rapidez das modificações tecnológicas e à aceleração do processo de inovação, associados à flexibilização das formas de produção (HARVEY, 1994). As transformações ocorridas a partir do estilo tecnológico de produção redefiniram as bases das regiões. Da mesma forma, modificaram a forma estrutural, funcional e de articulação dos territórios. A imposição de sistemas técnicos de ordem hegemônica reconfiguraram os espaços e tornaram uns mais dinâmicos do que outros nesse processo de transformação a partir da concentração e centralização dos capitais (SANTOS, 1996).

Nesse contexto, os últimos trinta anos do século $\mathrm{XX}$ foram ricos em acontecimentos e transformações socioeconômicas em todo o Sul do Brasil. A rapidez das modificações tecnológicas e a aceleração do processo de inovação, associadas à flexibilização das formas de produção, alteraram a distribuição das atividades econômicas no espaço desses territórios, tornando uns mais dinâmicos do que outros nesse processo de transformação, e fazendo desse, um processo desigual.

É nessa perspectiva que se justifica as análises das desigualdades regionais, no nosso caso do Sul do Brasil. Essa região passou por um processo intenso de tecnificação e modernização das áreas rurais a partir dos anos 1970, ocasionando uma urbanização generalizada e reestruturando a base produtiva das regiões. Essas reestruturações impactaram no desenvolvimento de outros segmentos econômicos, determinando que os setores urbanos (secundário e terciário) ampliassem significativamente sua participação na produção econômica regional. 


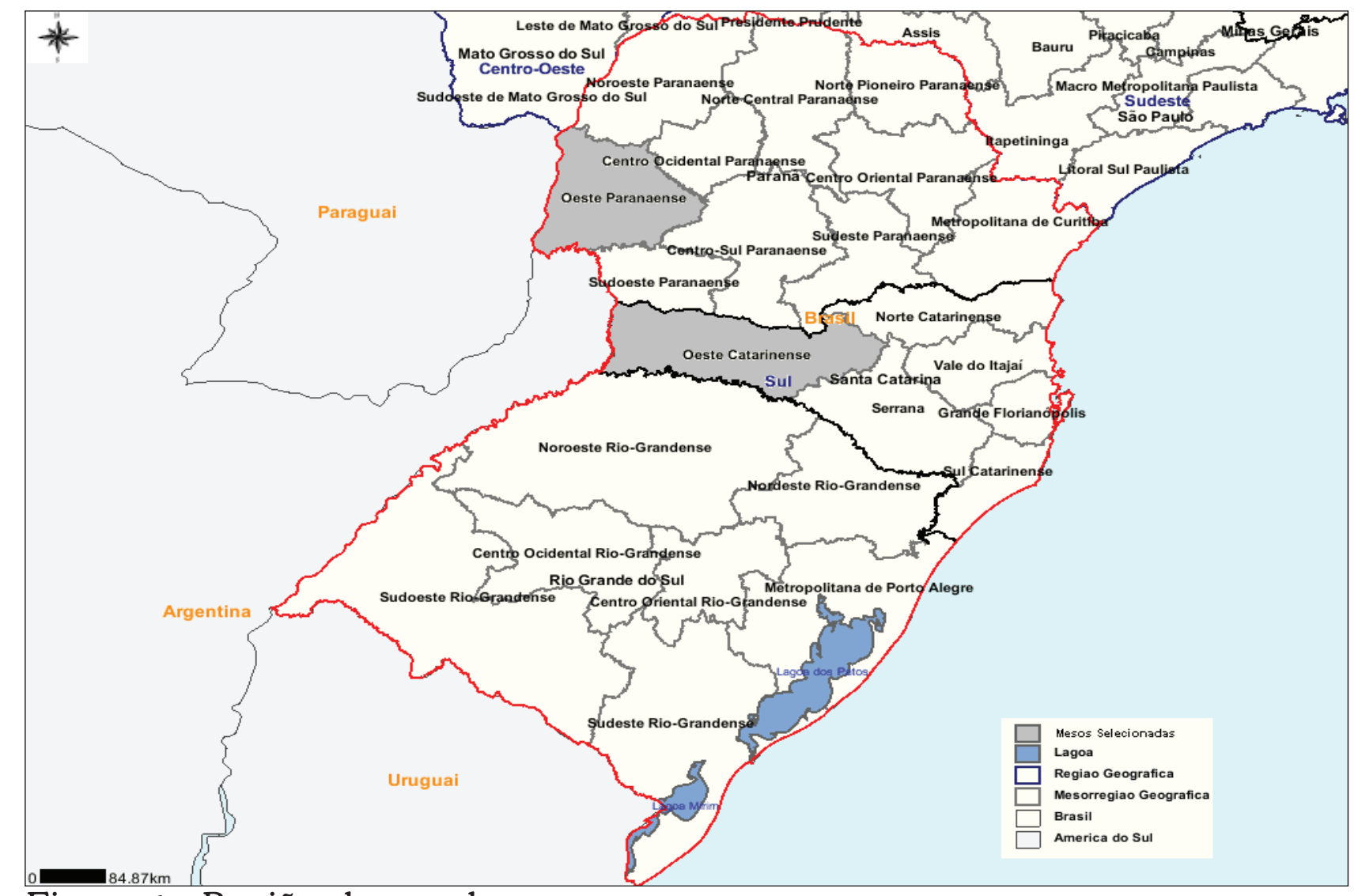

Figura 1 - Região de estudo

Fonte: Instituto Brasileiro de Geografia e Estatística (2006).

As duas mesorregiões analisadas tiveram suas terras ocupadas com colonos oriundos da mesorregião Noroeste Rio-Grandense. Isso ocorreu, pois segundo Bernardes (1997), os descendentes dos colonos tentam manter sua identidade enquanto agricultores familiares. Assim, quando não é mais possível economicamente a subdivisão da propriedade nas regiões de colonização mais antiga (do RS), passam eles a constituir a nova vanguarda do povoamento e se deslocam para as zonas pioneiras distantes. Nesse sentido, escasseando as terras virgens no Alto Uruguai (RS), avolumam a corrente que se dirige para o Oeste de Santa Catarina e para o Sudoeste e Oeste do Paraná. Segundo Lagemann (1998), houve uma expansão das antigas colônias europeias do Rio Grande do Sul em direção ao Noroeste Rio-Grandense na última década do século XIX e primeiras décadas do século XX. O Oeste Catarinense tornou-se, então, o local da próxima expansão desse fluxo populacional, entre 1910 e 1950, e o Oeste, Sudoeste e Sudeste do Paraná a partir de 1950. Vale dizer, o maior contingente populacional dessas mesorregiões seria natural do Rio Grande do Sul e de Santa Catarina no caso das mesorregiões paranaenses. Aliado a isso, o processo de ocupação da mesorregião Catarinense e das duas mesorregiões paranaenses referidas se deu com características semelhantes, principalmente, na forma da distribuição fundiária assentada em pequenas propriedades familiares rurais, e a policultura como forma de exploração econômica inicial, características 
essas ratificadas por diversos autores, tais como Bernardes (1997), Corrêa (1997) e Padis (2006).

Esse conjunto de semelhanças foi primordial para a escolha dessas mesorregiões para a análise. Mas, a despeito das similaridades de base, se comparamos o dinamismo socioeconômico dessas mesorregiões, no período 1970-2000, verifica-se um comportamento muito distinto entre elas, fato que poderá ser melhor visualizado nas Tabelas 1 e 2.

Tabela 1 - Valores absolutos e taxas de crescimento do PIB total, população residente total e PIB per capita das mesorregiões Oeste Catarinense, Oeste Paranaense e do Sul do Brasil - 1970/2000

\begin{tabular}{c|c|c|c|c|c|c|c|c|c|}
\hline \multirow{2}{*}{ Mesorregião } & \multicolumn{3}{|c|}{$\begin{array}{c}\text { PIB - TOTAL } \\
\text { (R\$ milhões) }\end{array}$} & \multicolumn{2}{c}{$\begin{array}{c}\text { População Residente Total } \\
\text { (mil pessoas) }\end{array}$} & \multicolumn{4}{c}{ PIB per capita } \\
\cline { 2 - 11 } & $\mathbf{1 9 7 0}$ & $\mathbf{2 0 0 0}$ & $\mathbf{\Delta} \%$ & $\mathbf{1 9 7 0}$ & $\mathbf{2 0 0 0}$ & $\mathbf{\Delta} \%$ & $\mathbf{1 9 7 0}$ & $\mathbf{2 0 0 0}$ & $\mathbf{\Delta} \%$ \\
\hline Oeste-SC & $1.616,87$ & $9.956,29$ & $\mathbf{5 1 5 , 7 8}$ & 744,27 & $1.115,38$ & $\mathbf{4 9 , 8 6}$ & $2.172,42$ & $8.926,39$ & $\mathbf{3 1 0 , 9 0}$ \\
Oeste-PR & $1.259,82$ & $9.395,28$ & $\mathbf{6 4 5 , 7 6}$ & 752,43 & $1.138,58$ & $\mathbf{5 1 , 3 2}$ & $1.674,34$ & $8.251,74$ & $\mathbf{3 9 2 , 8 4}$ \\
Sul do Brasil & $51.756,3$ & $193.534,3$ & $\mathbf{2 7 3 , 9 3}$ & $16.496,32$ & $25.108,62$ & $\mathbf{5 2 , 2 0}$ & $3.137,44$ & $7.708,19$ & $\mathbf{1 4 5 , 6 8}$ \\
\hline
\end{tabular}

Fonte: Ipeadata (2009).

Nota: PIB $=$ Valores em $\mathrm{R} \$ 1.000 .000,00$ de 2000, deflacionado pelo deflator implícito do PIB nacional.

A Tabela 1 apresenta os valores absolutos e as taxas de crescimento do Produto Interno Bruto (PIB) total, população residente total e PIB per capita das mesorregiões em análise, referentes aos anos de 1970 e 2000. Verifica-se que os indicadores selecionados nas duas mesorregiões apresentaram desempenho distinto e superior ao Sul do Brasil. Não que se esperassem índices de crescimento iguais, haja vista que o processo de desenvolvimento por si só é heterogêneo espacialmente, mas o grau de desigualdade das taxas de variação das distintas mesorregiões não pode deixar de surpreender. O Oeste Paranaense e o Oeste Catarinense apresentaram desempenho muito superior em relação ao PIB e ao PIB per capita, no período 1970-2000, se comparados ao Sul do Brasil. O crescimento da população total foi muito próximo, mas levemente inferior.

$\mathrm{Na}$ Tabela 2 é possível verificar o valor absoluto e as taxas de crescimento do PIB dos setores agropecuário, industrial e de serviços das mesorregiões em análise, referente aos anos de 1970 e 2000.

Conforme mostra a Tabela 2, as mesorregiões Oeste Paranaense e Oeste Catarinense apresentaram taxas de crescimento superiores às do Sul do Brasil em todos os setores do PIB. Enquanto o Oeste Catarinense e o Oeste Paranaense apresentaram crescimento de $305,11 \%$ e $178,78 \%$, respectivamente, no PIB agropecuário, o Sul do Brasil apresentou somente 94,77\% de crescimento entre 1970 e 2000. Para o setor industrial a disparidade foi ainda maior: o sul do Brasil cresceu $435,05 \%$ e as mesorregiões analisadas apresentaram um crescimento maior do que $1.000 \%$ no caso da mesorregião catarinense, e maior do que $2.200 \%$ na mesorregião paranaense. O desempenho do PIB de serviços também foi muito maior nessas duas mesorregiões quando comparado com o Sul do Brasil. 
Tabela 2 - Valor absoluto e taxas de crescimento do PIB agropecuário, industrial e de serviços das mesorregiões Oeste Catarinense, Oeste Paranaense e do Sul do Brasil - 1970/2000

\begin{tabular}{c|c|c|c|c|c|c|c|c|c}
\hline \multirow{2}{*}{ Mesorregião } & \multicolumn{3}{|c|}{$\begin{array}{c}\text { PIB agropecuário } \\
\text { (R\$ milhões) }\end{array}$} & \multicolumn{3}{c|}{$\begin{array}{c}\text { PIB industrial } \\
\text { (R\$ milhões) }\end{array}$} & \multicolumn{3}{c}{$\begin{array}{c}\text { PIB serviços } \\
\text { (R\$ milhões) }\end{array}$} \\
\cline { 2 - 11 } & $\mathbf{1 9 7 0}$ & $\mathbf{2 0 0 0}$ & $\mathbf{\Delta} \%$ & $\mathbf{1 9 7 0}$ & $\mathbf{2 0 0 0}$ & $\mathbf{\Delta} \%$ & $\mathbf{1 9 7 0}$ & $\mathbf{2 0 0 0}$ & $\mathbf{\Delta} \%$ \\
\hline Oeste-SC & 693,68 & $2.810,16$ & $\mathbf{3 0 5 , 1 1}$ & 377,51 & $4.187,19$ & $\mathbf{1 . 0 0 9 , 1 5}$ & 545,67 & $2.958,95$ & $\mathbf{4 4 2 , 2 6}$ \\
Oeste-PR & 568,86 & $1.585,87$ & $\mathbf{1 7 8 , 7 8}$ & 159,37 & $3.707,82$ & $\mathbf{2 . 2 2 6 , 5 3}$ & 531,59 & $4.101,59$ & $\mathbf{6 7 1}, \mathbf{5 7}$ \\
Sul do Brasil & $11.957,5$ & $23.289,9$ & $\mathbf{9 4 , 7 7}$ & $14.390,6$ & $76.997,6$ & $\mathbf{4 3 5 , 0 5}$ & $25.408,2$ & $79.858,0$ & $\mathbf{2 1 4 , 3 0}$ \\
\hline
\end{tabular}

Fonte: Ipeadata (2009).

Nota: PIB $=$ Valores em $\mathrm{R} \$ 1.000 .000,00$ de 2000 , deflacionado pelo deflator implícito do PIB nacional.

Nesse contexto, questiona-se: quais foram os subsetores responsáveis pelo desempenho superior dos macrossetores nessas duas mesorregiões? Para facilitar a visualização, os resultados serão agregados pelos macrossetores, iniciando pelo dinamismo do setor agropecuário, passando pelo setor industrial e finalizando pelo setor de serviços. As considerações finais sumariam este artigo; porém, antes, serão apresentados a base teórica e os elementos metodológicos que darão suporte a elas.

\section{Especialização e Desenvolvimento Regional}

A análise deste artigo será permeada pela ideia de que o desenvolvimento de uma região está diretamente relacionado com suas opções produtivas, ou melhor, com suas especializações. Assim, é preciso ressaltar que a especialização de uma região, em um ou mais segmentos, é tida como condição de desenvolvimento desde Adam Smith. Além disso, a especialização é um importante "indício" do potencial de uma região. E qual a importância em se identificar o potencial de uma região? Quando se identifica o potencial de uma região identificam-se, também, aqueles setores que, uma vez mobilizados/ fomentados, geram o maior benefício por unidade de custo.

Isso significa dizer, em primeiro lugar, que o "potencial de uma região" deve ser pensado como a capacidade da mesma em dar início e sustentação a processos de autonomia material e bem-estar crescentes dos agentes produtivos locais e de seus dependentes com base na mobilização do maior volume possível de recursos produtivos disponíveis internamente. Ou, ainda, dar início e sustentação a um processo de crescimento autopropelido, a um processo de crescimento onde os determinantes do sucesso e da competitividade de longo prazo vão sendo endogeneizados de forma crescente pelas firmas e pelos agentes produtivos locais. (PAIVA, 2004, p. 16).

Ao mesmo tempo, a especialização além de ser a manifestação da determinação primeira de "potencial", ela é a "capacidade mobilizatória" de um determinado setor, ou seja, o poder de "multiplicação" (no espaço e no tempo) do fomento ao mesmo. Paiva (2006) acrescenta que não há uma 
definição única para a categoria especialização. Entretanto, uma interpretação equivocada é a que identifica "especialização" a "monocultura" ou "monoatividade". Nessa pesquisa, utilizaremos a perspectiva de que, no processo de desenvolvimento, uma região pode ser multiespecializada, ou seja, as economias desenvolvidas tendem à multiespecialização, em contraposição às economias estagnadas e excluídas da divisão inter-regional do trabalho (que tendem à diversificação autárquica) e às economias satelizadas (que tendem à "monoespecialização").

Diferentemente de Adam Smith, Douglas North denomina as especializações como "modelo de base de exportação". Porém em ambos é possível encontrar características similares em suas teorias e que são apontadas por Paiva (2006): para Smith, a passagem da relação bifuncional entre "tamanho de mercado" e "divisão do trabalho", de uma contradição retardadora do processo de desenvolvimento, em um fator de alavancagem desse mesmo desenvolvimento só é possível através da solução exportadora. O que passa, necessariamente, por uma dupla identificação e mobilização: (a) dos segmentos internos capazes de produzir um excedente vis-à-vis à demanda regional; e (b) de comunidades externas aptas a demandar aquela produção excedente a um preço igual ou superior ao somatório dos custos efetivos de produção.

North [...] é o primeiro a reconhecer que a medida da eficácia da produção básica para o desenvolvimento regional é a emergência e consolidação de um amplo e diversificado segmento produtor de bens não básicos (não voltados à exportação, mas ao consumo interno) no território. Mais: segundo o autor, as demandas de insumos e de bens finais, associadas ao desenvolvimento regional da produção de bens básicos e não-básicos, devem conduzir a uma crescente diversificação da produção agropecuária, industrial e de serviços. O que irá se traduzir na diversificação e urbanização da pauta de exportação regional. Vale dizer: a diversificação é a meta e a medida do desenvolvimento (PAIVA, 2006, p. 5, grifo nosso).

Assim, em resumo, North (1961a) afirma que as regiões se desenvolvem melhor quando diversificam a pauta de produtos de exportação. Segundo o autor, os fatores mais importantes no desenvolvimento sustentado desses produtos são:

a) a dotação natural da região que dita seus produtos iniciais da exportação. Se essas dotações resultarem em uma vantagem comparativa tremenda em um produto que transborde outro, a consequência imediata será para que os recursos se concentrem em sua produção;

b) o caráter do setor de exportação. Nesse quesito, existem algumas características que influenciam significativamente no desenvolvimento do setor de exportação. Uma dessas características é a distribuição de renda regional. Quanto mais equitativo forem a distribuição de renda e fundiária, maiores serão os reflexos às demandas de bens e serviços na região. Investimentos serão induzidos e efetuados para atender essas novas demandas e novos centros de comércio se desenvolverão. Além disso, melhorias na qualificação educacional e investimentos em pesquisa serão 
induzidos nessas áreas objetivando melhorar sua posição comparativa e diversificar a base econômica.

Complementando, o setor de exportação tende a refletir-se no desenvolvimento do setor de transporte, de armazenamento, de indústrias complementares e de tecnologia. Se o setor de exportação incentivar o crescimento desses setores, e se a tecnologia, os custos de transporte e as dotações de recursos regionais permitirem que estes sejam produzidos localmente, então uma urbanização e uma especialização diversificadas serão promovidas. Ao contrário, se a região não tiver condições de produzir localmente, ela poderá importar de forma mais eficiente possível esses produtos.

c) e as mudanças nos custos de tecnologia e de transporte que podem alterar a vantagem comparativa da região. A mudança tecnológica tende a aumentar a taxa de retorno potencial da produção de outros bens e serviços, conduzindo à exploração de novos recursos e diversificando o rol de indústrias de exportação. O desenvolvimento dos transportes auxilia positivamente na diversificação produtiva e reduz os custos de transporte, consequentemente nos custos de produção, aumentando a vantagem comparativa dos produtos da exportação.

North (1977b) afirma ainda que o desenvolvimento de um setor de exportação ocorre primeiramente na agricultura, mas pode se expandir para os setores industrial e de serviços. O sucesso do desenvolvimento do setor exportador resultará em um aumento da renda da região e conduzirá a:

(1) Especialização e divisão do trabalho com ampliação do mercado regional; (2) O crescimento dos serviços auxiliares e indústrias subsidiárias para produzir e comercializar eficientemente o produto de exportação; (3) O desenvolvimento de indústrias locais para servir ao consumo local, algumas das quais podem, conduzir à ampliação da base de exportação em conseqüência da expansão dos mercados e do desenvolvimento de economias externas associadas a indústria de exportação; (4) Como uma conseqüência natural das condições acima, o crescimento das áreas e serviços urbanos; (5) Um investimento crescente na educação e na pesquisa para ampliar o potencial da região. (NORTH, 1977b, p. 341).

Assim, o crescimento regional bem-sucedido ocorre porque os desenvolvimentos iniciais no setor de exportação (especialização) levam gradualmente à diversificação da pauta de exportação (multiespecialização) e à ampliação na dimensão do mercado doméstico. Internamente, isso vai ocasionar uma variedade cada vez maior de indústrias e serviços locais, a ponto de incluir uma ampla gama de atividades econômicas. Com o sucessivo aumento das rendas, aumenta-se também o mercado interno, e a dimensão eficiente desses tipos de atividades cresce e algumas delas podem se tornar tão eficientes que podem se transformar em novas indústrias de exportação. A expansão bem-sucedida provoca um influxo de capital e de mão de obra; as proporções entre os fatores de produção modificam-se gradualmente para favorecer ainda mais a expansão contínua da região. As mudanças 
na proporção de combinação de fatores, a redução de custos induzida pelos investimentos na infraestrutura e a melhoria dos padrões culturais e profissionais, conduzem a uma diversificação ainda maior e à capacidade de expandir em outras atividades econômicas (NORTH, 1961b, p. 33). De acordo com a descrição anterior, o que sinteticamente ocorre durante o desenvolvimento do setor exportador é o que Hirschman denominou de backward and forward linkages, ou seja, efeitos de encadeamento para trás e para frente. De acordo com Hirschman (1961), o encadeamento para trás é fruto de um crescimento autônomo de um determinado setor (o exportador), motivado basicamente por causa de um novo investimento ou pelo aproveitamento da capacidade produtiva previamente existente. Esse encadeamento induz o crescimento de outros setores a ele relacionados, devido principalmente às pressões de demanda. Já os encadeamentos para frente, o motivo de sua ocorrência é a existência de um aumento da produção de um determinado fator que provoca a elevação da produção de outros setores em virtude do excesso de oferta do produto do setor inicial (o mesmo setor exportador). Assim, esses encadeamentos podem se transformar e formar uma cadeia produtiva regional.

Nesse sentido, Paiva (2004) ressalta que toda especialização regional deve ser pensada em sua dimensão de cadeia. Segundo o autor, as vantagens competitivas absolutas criadas pela especialização estimulam um processo de integração regional crescente das cadeias produtivas à qual pertence o produto especializado que deu início ao processo. Além disso, esse processo de especialização em cadeia presume a endogeneização dos segmentos produtores de máquinas, equipamentos e insumos (D1 do Kalecki), haja vista que essa endogeneização é a persistente redução dos custos de produção dos elos a jusante.

Hilhorst (1975) adiciona que outra característica positiva da especialização é a capacidade de causar transformações nas relações de dependência e poder, portanto, ocasionar um maior grau de interdependência regional. Assim, enquanto as relações de dependência são uma característica de integração vertical, as relações de interdependência são características da integração horizontal.

Nesse contexto, a multiespecialização produtiva (North) feita de forma equitativa tende a se refletir em uma melhor distribuição de renda (Kalecki) e empregos (divisão do trabalho de Smith), melhorando o influxo da renda, a qualidade de vida e a competição mercantil regionais. Assim, a multiespecialização regional, a integração econômica e a diversificação produtiva são três movimentos que sintetizam a divisão regional do trabalho e a ampliação dessa divisão social do trabalho dentro da reprodução ampliada do capital, culminando no desenvolvimento regional. Essa será a ideia de desenvolvimento regional utilizada neste artigo.

\section{Elementos Metodológicos}

Para responder aos questionamentos supracitados, optou-se por utilizar como instrumental de análise regional - o instrumental estrutural-diferencial, 
tradicionalmente conhecido como shift and share, para avaliar o dinamismo setorial dessas mesorregiões entre 1970 e 2000.

As variáveis utilizadas no instrumental serão: para analisar o setor primário, o valor bruto (monetário) da produção agropecuária, VBPA, disponibilizada pelos Censos Agropecuários de 1970 e 1996, tendo sido os valores de 1970 deflacionados pelo IGP-DI para o ano de 1996, tornando assim os dados comparáveis. Já, para analisar os setores secundário e terciário, a variável escolhida foi o número de pessoas ocupadas (PO) por ramos de atividades, divulgado pelos microdados dos Censos Demográficos de 1970 e 2000. Em ambos os casos, a disponibilização foi feita pelo Instituto Brasileiro de Geografia e Estatística (IBGE). A descrição detalhada do método shift and share encontra-se no Apêndice A.

Nesse contexto, a próxima seção apresenta os resultados do setor agropecuário das mesorregiões Oeste Catarinense e Oeste Paranaense.

\section{Dinamismos do Setor Agropecuário entre 1970 e 2000}

O setor agropecuário das mesorregiões em análise, e de todo o Sul do Brasil, passou por grandes transformações estruturais e técnicas após 1970. Uma síntese desse processo é apresentada por Moreira (2004). Na interpretação do autor, os planos de desenvolvimento do Governo Federal, os famosos I e II PND, tiveram grande influência - se não a principal - nas transformações do campo. O I PND, em 1972, introduziu a vertente da modernização tecnológica, e o II PND, entre 1975 e 1979, criou e consolidou um setor industrial para a agricultura, isto é, um setor produtor e fornecedor ao campo de produtos industriais - de máquinas e equipamentos, fertilizantes e produtos agrícolas - e com implementação de uma rede de transportes, comunicações e distribuição de energia elétrica, integrou a agricultura à indústria dando origem a agroindústria moderna existente do Brasil contemporâneo.

Nas décadas de 1980 e 1990 houve continuidade nesse processo de tecnificação do complexo agroindustrial brasileiro, promovendo a autonomização das diferentes fases do processo agroindustrial como ramos especializados. O desenvolvimento do setor agroindustrial se deu a partir de efeitos de encadeamentos entre a agricultura, a indústria e o setor de serviços: a agropecuária relacionando-se à montante com as indústrias de produtos agrícolas e à jusante com as indústrias de transformação, tendo estas também demandado serviços diversos, influenciando no desenvolvimento do setor terciário. Porém, o processo de tecnificação do campo foi amplamente poupador de mão de obra, principalmente nos cultivos de grãos, que foram substituídos por tratores e equipamentos em geral.

Dados dos Censos Agropecuários apresentam o número de tratores nessas mesorregiões, e essa informação dá ideia da "dimensão" da tecnificação do campo desse território: o Oeste Catarinense apresentou um crescimento de 1.697,64\% entre 1970 e 1996, e o Oeste Paranaense de 1.232,46\% no mesmo período.

Outra consequência de todo esse processo de "modernização" do campo foi a redução do número de pequenos estabelecimentos rurais no período 1970-1996 nas duas mesorregiões em análise, conforme Tabela 3. 


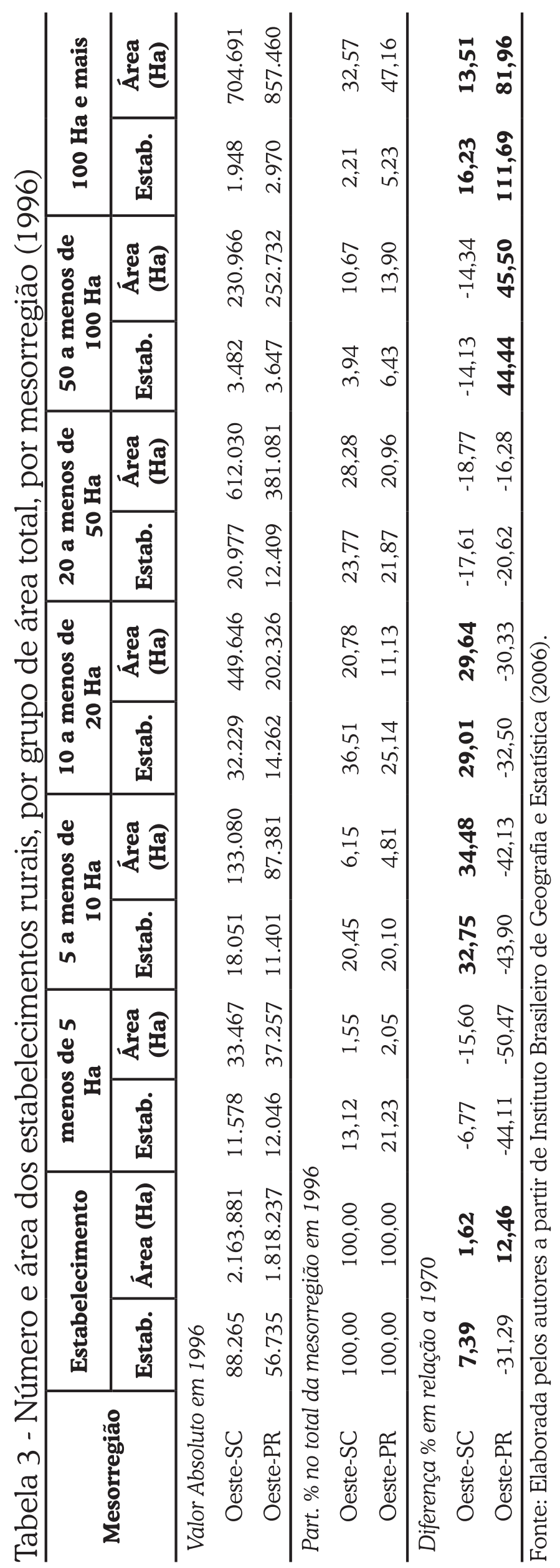


Pela Tabela 3, verifica-se que houve uma redução do número de estabelecimentos totais no Oeste Paranaense na ordem de $-31,29 \%$. Porém, apesar da diminuição dos estabelecimentos, houve aumento da área total. Este binômio - aumento da área/diminuição do número de propriedades - já expressa a tendência à elevação da área média e, por extensão, da concentração fundiária nessa mesorregião. Porém, o Oeste Catarinense apresentou crescimento do número de estabelecimentos totais, na ordem de 7,39\% entre 1970 e 2000 . O mais interessante é que esse aumento foi maior entre os estabelecimentos de pequeno e médio porte, de 5 a 20 ha, crescendo em média 30\% o número de estabelecimentos e de área.

Ao contrário da mesorregião Oeste Catarinense, o Oeste Paranaense apresentou a maior parcela da redução de área e de estabelecimentos totais nos grupos de menores áreas. Os estabelecimentos de maiores áreas foram os que mais cresceram nessa mesorregião.

Acredita-se que essas variações no tamanho e número dos estabelecimentos estejam relacionadas às atividades que cada mesorregião se especializou nesse período. O Quadro 1 mostra quais foram as atividades que ganharam expressão relativa (medida em pontos percentuais) no valor da produção entre 1970 e 1996.

Conforme mostra o Quadro 1, entre as atividades de maior expressão nas mesorregiões Oeste/SC e Oeste/PR, o binômio milho e suínos era responsável pela maior parte do valor da produção, representando $49,90 \%$ do valor da produção no Oeste/SC e 48,62\% no Oeste/PR.

Já, no período 1970-1996, a cultura da soja foi a que mais ganhou destaque na mesorregião Oeste Paranaense (de 10,99\% para 34,17\%). Em segundo lugar, com maior crescimento relativo, ficou a avicultura passando de $2,71 \%$ para $17,07 \%$.

No Oeste Catarinense quem mais ganhou destaque foi a avicultura. Essa atividade passou de uma representação de 4,08\%, em 1970, para 23,03\%, em 1996, sendo que a suinocultura continuou sendo a atividade de maior destaque nessa mesorregião em 1996, com 31,51\%. 


\begin{tabular}{|c|c|c|c|}
\hline \multicolumn{2}{|c|}{ Oeste - SC } & \multicolumn{2}{|c|}{ Oeste - PR } \\
\hline 1970 & 1996 & 1970 & 1996 \\
\hline Prod. & Prod. & Prod. & Prod. \\
\hline Suíno.........24,98 & Suíno.......31,51 & Milho........28,15 & Soja..........34,17 \\
\hline Milho.........24,92 & Aves.........23,03 & Suíno.........20,47 & Aves.........17,07 \\
\hline Mandioca....9,35 & Milho.......13,86 & Soja...........10,99 & Milho.......16,56 \\
\hline Leite............8,48 & Leite............6,38 & Feijão...........9,14 & Suíno.......11,18 \\
\hline Feijão..........6,17 & Maçã.............5,04 & Mandioca....7,06 & Leite..........6,19 \\
\hline Trigo...........5,91 & Soja................3,68 & Leite.............5,21 & Bovino.........5,37 \\
\hline Aves............4,08 & Fumo............3,55 & Arroz.............3,92 & Trigo............3,24 \\
\hline Bovino..........3,34 & Bovino..........3,54 & Bovino..........3,54 & Mandioca....2,80 \\
\hline Soja................3,04 & Feijão...........3,50 & Trigo.............3,45 & Feijão...........0,71 \\
\hline Uva..............1,73 & Mandioca....2,15 & Aves...........2,71 & Fumo............, 0,68 \\
\hline SOMA.........91,99 & SOMA.........96,23 & SOMA.........94,64 & SOMA.........97,97 \\
\hline
\end{tabular}

Quadro 1 - Participação dos principais produtos da agropecuária sobre o total do valor da produção agropecuária, por mesorregião (1970/1996)

Fonte: Elaborada pelos autores a partir de Instituto Brasileiro de Geografia e Estatística (2006, 1974a, 1974b, 1974c).

Nota: O valor da produção agropecuária analisado não inclui a silvicultura e a extração vegetal.

Será a cultura da soja mais "excludente" do que a suinocultura e a avicultura, haja vista que, no Oeste Paranaense, houve uma redução dos estabelecimentos totais? Os indícios são de que essas duas últimas atividades são mais intensivas em mão de obra e menos intensivas em território, deprimindo relativamente às tendências à concentração da propriedade e ao êxodo rural. Diferentemente, as culturas de grãos, ao exigirem uma maior relação capital/trabalho e terra/ trabalho, dificultam a permanência do pequeno agricultor no meio rural.

Para além da diferença no número de estabelecimentos rurais e na mudança hierárquica das atividades de maior destaque no período 19701996, é interessante analisar o dinamismo relativo das principais atividades agropecuárias das mesorregiões em análise. Para tanto, serão apresentados os resultados do método estrutural-diferencial.

Quanto ao dinamismo das atividades agropecuárias do Oeste Catarinense, ele está apresentado na Tabela 4, e constata-se que o VBPA total dessa mesorregião cresceu $139,81 \%$ no período 1970-1996. Com exceção do arroz, as atividades dessa mesorregião que apresentaram diminuição em seus VBPA foram as mesmas que apresentaram decréscimo na macrorregião (o Sul do Brasil) de referência, como, por exemplo, a mandioca, o trigo e a uva. As demais atividades apresentaram crescimento e em algumas esse comportamento foi significativo, como foi o caso das aves, com 1.227,39\% (que passou a ocupar o segundo maior VBPA mesorregional de 1996), a maçã, com 30.025,45\%, e o 
fumo, com 527,21\%. A suinocultura dessa mesorregião, se comparada as outras três mesorregiões, foi a única a apresentar crescimento superior a taxa de crescimento da suinocultura do Sul do Brasil, 196,72\% contra 27,03\%, respectivamente. Com isso, essa atividade consolidou-se como o maior VBPA, seguido das aves e do milho, atividades que formam a base das principais cadeias produtivas dessa mesorregião.

O Oeste Catarinense apresentou componente diferencial total positivo, apontando para vantagens competitivas específicas que deram a essa mesorregião um dinamismo superior se comparado com a macrorregião de referência (o Sul do Brasil). Ao lado disso, o valor da variação total absoluta não deixa de surpreender.

O saldo do componente setorial dessa mesorregião - mesmo que pequeno - foi negativo, indicando que a mesorregião não foi beneficiada por sua estrutura produtiva inicial. O valor positivo da componente setorial da avicultura foi mais do que compensado pelos valores negativos do trigo, da mandioca, do milho e do feijão. O que prevaleceu nessa mesorregião foi o expressivo número de atividades com o componente diferencial positivo. As atividades com maiores vantagens competitivas foram os suínos e as aves. A taxa de crescimento do VBPA dessas duas atividades foi muito superior à taxa de crescimento desses mesmos setores no Sul do Brasil, de 1.227,39\% e 196,72\% das aves e suínos, respectivamente, nessa mesorregião, em contraste com os $466,68 \%$ e $27,03 \%$ apresentados, respectivamente, nos mesmos setores, no Sul do Brasil.

Tabela 4 - Resultados do modelo estrutural-diferencial para a agropecuária da mesorregião Oeste Catarinense (1970/1996)

\begin{tabular}{|c|c|c|c|c|c|c|c|c|}
\hline Atividade & $\begin{array}{c}\text { VBPA } \\
1970 \\
\text { (R\$ } \\
\text { mil) } \\
\end{array}$ & $\begin{array}{l}\text { Comp. } \\
\text { "nacional" }\end{array}$ & $\begin{array}{l}\text { Comp. } \\
\text { setorial }\end{array}$ & $\begin{array}{l}\text { Comp. } \\
\text { diferencial }\end{array}$ & $\begin{array}{c}\text { VBPA } \\
1996 \\
\text { (R\$ mil) }\end{array}$ & $\begin{array}{c}\text { Variação } \\
\text { total } \\
\text { absoluta }\end{array}$ & $\begin{array}{c}\text { Variação } \\
\% \\
\text { no Sul } \\
\text { do Brasil }\end{array}$ & $\begin{array}{c}\text { Variação } \\
\text { \% da } \\
\text { meso }\end{array}$ \\
\hline Arroz & 8.827 & 3.332 & -588 & -8.644 & 2.927 & -5.900 & 31,09 & $-66,84$ \\
\hline Aves & 26.436 & 9.978 & 113.393 & 201.098 & 350.905 & 324.469 & 466,68 & $1.227,39$ \\
\hline Bovino & 21.649 & 8.171 & -1.748 & 25.890 & 53.962 & 32.312 & 29,67 & 149,25 \\
\hline Feijão & 39.953 & 15.080 & -32.218 & 30.559 & 53.375 & 13.422 & $-42,89$ & 33,59 \\
\hline Fumo & 8.619 & 3.253 & 12.749 & 29.437 & 54.059 & 45.440 & 185,66 & 527,21 \\
\hline Leite & 54.920 & 20.729 & 937 & 20.645 & 97.231 & 42.312 & 39,45 & 77,04 \\
\hline Maçã & 255 & 96 & 19.436 & 57.087 & 76.875 & 76.619 & $7.654,23$ & $30.025,45$ \\
\hline Mandioca & 60.593 & 22.870 & -35.591 & -15.093 & 32.779 & -27.814 & $-20,99$ & $-45,90$ \\
\hline Milho & 161.452 & 60.939 & -34.464 & 23.242 & 211.169 & 49.717 & 16,40 & 30,79 \\
\hline Soja & 19.703 & 7.437 & 33.967 & -5.039 & 56.068 & 36.365 & 210,14 & 184,56 \\
\hline Suíno & 161.813 & 61.075 & -17.344 & 274.583 & 480.126 & 318.313 & 27,03 & 196,72 \\
\hline Trigo & 38.277 & 14.447 & -45.676 & -1.886 & 5.163 & -33.114 & $-81,59$ & $-86,51$ \\
\hline Uva & 11.214 & 4.233 & -5.679 & -2.163 & 7.604 & -3.610 & $-12,90$ & $-32,19$ \\
\hline Outras & 21.773 & 8.218 & -7.750 & 19.460 & 41.701 & 19.928 & 2,15 & 91,53 \\
\hline TOTAL & 635.484 & 239.858 & -576 & 649.176 & 1.523 .943 & 888.459 & 37,74 & 139,81 \\
\hline
\end{tabular}

Fonte: Elaborada pelos autores a partir de Instituto Brasileiro de Geografia e Estatística (2006). 
Analisando a variação total absoluta das atividades do Oeste Catarinense, verifica-se que essa mesorregião apresentou desempenhos positivos em dez das quatorze atividades analisadas. Os principais destaques foram a avicultura, suinocultura, maçã, milho, fumo e leite (quase todas especializações significativas no período). A quase totalidade dessas atividades (a exceção é o milho, um grão que pode ser produzido em larga escala, mas, normalmente, é produzido em consórcio com aves e suínos, em pequenas propriedades) é intensiva em mão de obra, adequadas, portanto, a estabelecimentos de pequeno e médio portes, o que ajuda a explicar o aumento do total de estabelecimentos dessa mesorregião no período 1970-1996.

Quanto ao comportamento do VBPA do Oeste Paranaense, verificase que o crescimento do VBPA total no período 1970-1996 foi de 117,11\%, conforme a Tabela 5. Das mesorregiões em análise, foi a segunda com o maior crescimento, ficando atrás somente do Oeste Catarinense, que ampliou seu VBPA em 139,81\%. Apesar de o arroz, o feijão, a maçã e a mandioca terem apresentado diminuição do VBPA, o crescimento das demais atividades foi mais que compensador, sendo o crescimento das aves, de $1.254,94 \%$, e da soja, de $568,96 \%$, o mais representativo.

Tabela 5 - Resultados do modelo estrutural-diferencial para a agropecuária da mesorregião Oeste Paranaense (1970/1996)

\begin{tabular}{|c|c|c|c|c|c|c|c|c|}
\hline Atividade & $\begin{array}{l}\text { VBPA } \\
1970 \\
\text { (R\$ } \\
\text { mil) }\end{array}$ & $\begin{array}{l}\text { Comp. } \\
\text { "nacional" }\end{array}$ & $\begin{array}{l}\text { Comp. } \\
\text { setorial }\end{array}$ & $\begin{array}{l}\text { Comp. } \\
\text { diferencial }\end{array}$ & $\begin{array}{c}\text { VBPA } \\
1996 \\
\text { (R\$ mil) }\end{array}$ & $\begin{array}{l}\text { Variação } \\
\text { total } \\
\text { absoluta }\end{array}$ & $\begin{array}{c}\text { Variação } \\
\% \\
\text { no Sul } \\
\text { do Brasil }\end{array}$ & $\begin{array}{c}\text { Variação } \\
\text { \% da } \\
\text { meso }\end{array}$ \\
\hline Arroz & 18.961 & 7.157 & -1.262 & -21.573 & 3.283 & -15.678 & 31,09 & $-82,69$ \\
\hline Aves & 13.114 & 4.950 & 56.251 & 103.373 & 177.687 & 164.573 & 466,68 & $1.254,94$ \\
\hline Bovino & 17.114 & 6.460 & -1.382 & 33.714 & 55.906 & 38.792 & 29,67 & 226,67 \\
\hline Feijão & 44.193 & 16.680 & -35.636 & -17.818 & 7.419 & -36.774 & $-42,89$ & $-83,21$ \\
\hline Fumo & 4.363 & 1.647 & 6.453 & -5.413 & 7.049 & 2.687 & 185,66 & 61,58 \\
\hline Leite & 25.193 & 9.509 & 430 & 29.244 & 64.375 & 39.182 & 39,45 & 155,53 \\
\hline Maçã & 6 & 2 & 493 & -497 & 5 & -1 & $7.654,23$ & $-19,74$ \\
\hline Mandioca & 34.158 & 12.893 & -20.064 & 2.153 & 29.140 & -5.018 & $-20,99$ & $-14,69$ \\
\hline Milho & 136.130 & 51.381 & -29.058 & 13.924 & 172.377 & 36.247 & 16,40 & 26,63 \\
\hline Soja & 53.158 & 20.064 & 91.641 & 190.742 & 355.605 & 302.447 & 210,14 & 568,96 \\
\hline Suíno & 99.008 & 37.370 & -10.612 & -9.441 & 116.324 & 17.316 & 27,03 & 17,49 \\
\hline Trigo & 16.693 & 6.301 & -19.920 & 30.594 & 33.667 & 16.974 & $-81,59$ & 101,69 \\
\hline Uva & 652 & 246 & -330 & 562 & 1.129 & 478 & $-12,90$ & 73,32 \\
\hline Outras & 16.574 & 6.256 & -5.899 & -237 & 16.693 & 119 & 2,15 & 0,72 \\
\hline TOTAL & 479.317 & 180.914 & 31.105 & 349.327 & 1.040 .662 & 561.345 & 37,74 & 117,11 \\
\hline
\end{tabular}

Fonte: Elaborada pelos autores a partir de Instituto Brasileiro de Geografia e Estatística (2006). 
Porém, o que mais impressiona no Oeste Paranaense é o saldo positivo apresentado tanto pelo componente setorial quanto pelo componente diferencial. Essa foi a única mesorregião, entre as analisadas, a apresentar ambos os componentes positivos. Essa mesorregião tem uma dinâmica distinta: ela se especializou em atividades que o Sul do Brasil apresentou performances negativas, como foi o caso do trigo, por exemplo, e comportamentos acima da média "nacional" em boa parte das demais atividades. Esses resultados indicam que essa mesorregião se beneficiou de sua estrutura original, ampliando a especialização em setores em que já era especializada em 1970. A variação total absoluta da soja, das aves e do leite mostra que foram essas atividades as que mais contribuíram nesse desempenho.

Essa mesorregião se beneficiou de sua estrutura produtiva inicial, mas a base do seu desempenho está em suas vantagens competitivas. O saldo do componente diferencial foi muito superior ao do componente setorial, o que comprova essa afirmação. As atividades das aves, da soja, dos bovinos, do trigo e do leite foram as que mais se destacaram nesse desempenho.

Nesse contexto, analisando o adicional esperado de VBPA de cada mesorregião, em função do aumento do mercado/demanda interno(a) (componente nacional ou macro-regional), e o adicional efetivo (variação total absoluta), verifica-se que o melhor desempenho foi da mesorregião Oeste Catarinense, que apresentou um VBPA 3,70 vezes maior do que o esperado. No Oeste Paranaense esse desempenho foi 3,10 vezes maior do que o esperado.

\section{Dinamismos do Setor Industrial entre 1970 e 2000}

Boa parte da dinâmica industrial dessas duas mesorregiões está diretamente relacionada com a transformação da produção agropecuária, vale dizer, está baseada em agroindústrias. Como já apontado, esse dinamismo foi influenciado pelas políticas do Governo Federal, da década de 1970, de modernização e reorganização de agroindústrias, como as de carne, soja, entre outras, assim como pelas políticas de apoio à diversificação das exportações. Essas características possibilitaram a entrada de várias corporações transnacionais interessadas na internacionalização da agricultura brasileira, através da sua integração no projeto de desenvolvimento mundial do complexo agroindustrial por elas comandado. Nesse contexto, houve a demanda por máquinas, implementos agrícolas e insumos modernos (fertilizantes, sementes, pesticidas, etc.) estimulada durante o processo de mecanização/modernização do campo, exigindo que novas atividades industriais se desenvolvessem (BRUM, 1988; ESPÍNDOLA, 1999).

Mas não somente a dinâmica do setor agroindustrial influenciou no dinamismo industrial dessas mesorregiões. O próprio crescimento das áreas urbanas e da população total desses territórios exigiu o desenvolvimento e ampliação de muitos setores além do alimentício, como por exemplo, do vestuário, da construção civil, do mecânico, entre vários outros. Porém, 
coloca-se um questionamento: quais desses setores foram mais dinâmicos nessas mesorregiões? Subsidiando argumentos iniciais à questão, a Tabela 6 apresenta os resultados do modelo estrutural-diferencial para o setor industrial do Oeste Catarinense, e nota-se que essa mesorregião cresceu mais do que a média do Sul do Brasil entre 1970 e 2000. Com um crescimento no total das pessoas ocupadas no setor industrial de 349,54\%, nesse período, essa mesorregião passou de 24.338 para 109.410 pessoas ocupadas. O setor que mais empregava em 2000 era a indústria de produtos alimentares, com $33.192 \mathrm{PO}(1.001,26 \%$ de crescimento), seguida da construção civil, com 27.408 (376,16\% de crescimento), e das indústrias de madeira, com 8.794 PO (4,8\% de crescimento). Já, a indústria do vestuário foi a que apresentou o maior crescimento percentual, 6.629,63\% no período, e empregava 5.451 pessoas em 2000.

Tabela 6 - Resultados do modelo estrutural-diferencial para a indústria da mesorregião Oeste Catarinense (1970/2000)

\begin{tabular}{|c|c|c|c|c|c|c|c|c|}
\hline Atividade do setor industrial & $\begin{array}{c}\text { PO } \\
1970\end{array}$ & $\begin{array}{l}\text { Comp. } \\
\text { "nac." }\end{array}$ & $\begin{array}{l}\text { Comp. } \\
\text { setorial }\end{array}$ & $\begin{array}{l}\text { Comp. } \\
\text { Difer. }\end{array}$ & $\begin{array}{c}\text { PO } \\
2000\end{array}$ & $\begin{array}{c}\text { Variação } \\
\text { total } \\
\text { absoluta }\end{array}$ & $\begin{array}{c}\text { Var. \% } \\
\text { no Sul/ } \\
\text { BR }\end{array}$ & $\begin{array}{c}\text { Variação } \\
\text { \% da } \\
\text { meso }\end{array}$ \\
\hline \multicolumn{9}{|l|}{ EXTRAÇÃO MINERAL } \\
\hline $\begin{array}{l}\text { Ext.e apar. de ped. e out. mat. } \\
\text { cons. }\end{array}$ & 306 & 652 & -679 & 176 & 455 & 149 & $-8,68$ & 48,69 \\
\hline Extração de petróleo e gás natural & 0 & 0 & 0 & 0 & 0 & 0 & 503,20 & 0,00 \\
\hline Extração de carvão-de-pedra & 21 & 45 & -56 & -10 & 0 & -21 & $-53,27$ & $-100,00$ \\
\hline $\begin{array}{l}\text { Exp. de salinas e fontes } \\
\text { hidrominerais }\end{array}$ & 0 & 0 & 0 & 0 & 59 & 0 & $1.184,21$ & 0,00 \\
\hline $\begin{array}{l}\text { Ext. e beneficiamento de outros } \\
\text { min. }\end{array}$ & 0 & 0 & 0 & 0 & 10 & 0 & 56,42 & 0,00 \\
\hline Faiscação e garimpagem & 0 & 0 & 0 & 0 & 14 & 0 & $-74,49$ & 0,00 \\
\hline \multicolumn{9}{|l|}{ IND. DE TRANSFORMAÇÃO } \\
\hline Ind. metalúrgica & 668 & 1.424 & 59 & 2.591 & 4.742 & 4.074 & 222,00 & 609,88 \\
\hline Ind. mecânica & 697 & 1.486 & 573 & 53 & 2.809 & 2.112 & 295,41 & 303,01 \\
\hline Ind. de material elétrico e de com. & 33 & 70 & 131 & 340 & 574 & 541 & 608,75 & $1.639,39$ \\
\hline Ind. de material de transporte & 177 & 377 & 945 & -852 & 647 & 470 & 746,99 & 265,54 \\
\hline Ind. de minerais não metálicos & 784 & 1.671 & -724 & 375 & 2.106 & 1.322 & 120,80 & 168,62 \\
\hline Ind. de borracha & 4 & 9 & 7 & 172 & 191 & 187 & 381,40 & $4.675,00$ \\
\hline Ind. de fumo & 31 & 66 & -29 & 48 & 116 & 85 & 119,86 & 274,19 \\
\hline Ind. de papel e papelão & 1.065 & 2.270 & -158 & 764 & 3.941 & 2.876 & 198,31 & 270,05 \\
\hline Ind. de mobiliário & 1.207 & 2.573 & 381 & 4.154 & 8.315 & 7.108 & 244,77 & 588,90 \\
\hline Ind. de madeira & 8.391 & 17.887 & -15.929 & -1.555 & 8.794 & 403 & 23,34 & 4,80 \\
\hline $\begin{array}{l}\text { Ind. domiciliárias de artigos de } \\
\text { palha }\end{array}$ & 0 & 0 & 0 & 0 & 0 & 0 & $-21,61$ & 0,00 \\
\hline $\begin{array}{l}\text { Ind. de couro, peles e prod. } \\
\text { similares }\end{array}$ & 234 & 499 & -258 & 14 & 488 & 254 & 102,75 & 108,55 \\
\hline Ind. de materiais plásticos & 0 & 0 & 0 & 0 & 1.566 & 0 & 897,95 & 0,00 \\
\hline Ind. de prod. der. do pet. e carvão & 14 & 30 & -16 & 50 & 77 & 63 & 96,40 & 450,00 \\
\hline Ind. têxtil & 100 & 213 & -67 & 918 & 1.164 & 1.064 & 146,22 & $1.064,00$ \\
\hline
\end{tabular}


conclusão...

\begin{tabular}{|c|c|c|c|c|c|c|c|c|}
\hline Atividade do setor industrial & $\begin{array}{c}\text { PO } \\
1970\end{array}$ & $\begin{array}{l}\text { Comp. } \\
\text { "nac." }\end{array}$ & $\begin{array}{l}\text { Comp. } \\
\text { setorial }\end{array}$ & $\begin{array}{l}\text { Comp. } \\
\text { Difer. }\end{array}$ & $\begin{array}{c}\text { PO } \\
2000\end{array}$ & $\begin{array}{c}\text { Variação } \\
\text { total } \\
\text { absoluta }\end{array}$ & $\begin{array}{c}\text { Var. \% } \\
\text { no Sul/ } \\
\text { BR }\end{array}$ & $\begin{array}{c}\text { Variação } \\
\text { \% da } \\
\text { meso }\end{array}$ \\
\hline \multicolumn{9}{|l|}{ IND. DE TRANSFORMAÇÃO } \\
\hline Ind. domiciliárias têxteis & 24 & 51 & -74 & -1 & 0 & -24 & $-95,08$ & $-100,00$ \\
\hline Ind. do vestuário & 81 & 173 & 1.234 & 3.963 & 5.451 & 5.370 & $1.736,72$ & $6.629,63$ \\
\hline Ind. dos calçados & 369 & 787 & 569 & -525 & 1.199 & 830 & 367,31 & 224,93 \\
\hline Ind. de bebidas e álcoois & 206 & 439 & -433 & 349 & 561 & 355 & 3,08 & 172,33 \\
\hline Ind. editorial e gráfica & 198 & 422 & 126 & 719 & 1.465 & 1.267 & 276,88 & 639,90 \\
\hline Ind. de prod. farmac. e medicinais & 59 & 126 & 2 & -26 & 161 & 102 & 217,33 & 172,88 \\
\hline Ind. química & 40 & 85 & 3 & 6 & 134 & 94 & 220,85 & 235,00 \\
\hline Ind. de produtos alimentares & 3.014 & 6.425 & 669 & 23.084 & 33.192 & 30.178 & 235,36 & $1.001,26$ \\
\hline $\begin{array}{l}\text { Outras classes da indústria de } \\
\text { transf. }\end{array}$ & 314 & 669 & 551 & -153 & 1.381 & 1.067 & 388,57 & 339,81 \\
\hline CONSTRUÇÃO CIVIL & 5.756 & 12.270 & -674 & 10.056 & 27.408 & 21.652 & 201,46 & 376,16 \\
\hline \multicolumn{9}{|l|}{ SIUP } \\
\hline $\begin{array}{l}\text { Prod. e dist. de energia elétrica } \\
\text { e gás. }\end{array}$ & 466 & 993 & -681 & 630 & 1.408 & 942 & 66,93 & 202,15 \\
\hline $\begin{array}{l}\text { Abast. de água e serviço de } \\
\text { esgoto }\end{array}$ & 79 & 168 & 197 & 547 & 992 & 913 & 463,08 & $1.155,70$ \\
\hline TOTAL DA INDÚSTRIA & 24.338 & 51.881 & -14.331 & 45.883 & 109.410 & 83.433 & 213,17 & 349,54 \\
\hline
\end{tabular}

No geral, o Oeste Catarinense apresentou taxas de crescimento maiores do que os setores do Sul do Brasil, com maiores taxas de crescimento, ou seja, especializou-se em setores que "nacionalmente" tiveram bons desempenhos. Tanto que nenhum setor industrial dessa mesorregião apresentou taxas negativas, com exceção das indústrias de extração de carvão-de-pedra e das indústrias domiciliárias têxteis, que tinham um pequeno número de pessoas ocupadas em 1970, e nenhuma pessoa ocupada em 2000.

O Oeste Paranaense apresentou crescimento de $395,82 \%$ no número de pessoas ocupadas no setor industrial entre 1970 e 2000, passando de 16.416 para 81.394. Dos setores que mais ocupavam pessoas em 2000, destacavam-se o setor da construção civil, com $29.925 \mathrm{PO}$, as indústrias de produtos alimentares, com $15.900 \mathrm{PO}$, as indústrias do mobiliário, com 5.413 PO, e as indústrias de vestuário, com 5.246 PO. Essa última foi a que apresentou o maior crescimento percentual no período, com $32.687,50 \%$, seguida de abastecimento de água e serviço de esgoto, com $6.738,46 \%$, e das indústrias de materiais plásticos, com $5.112,50 \%$. Porém, a última pouco se destacou na ocupação total de pessoas.

O Oeste Paranaense apresentou crescimento da população industrial $85 \%$ superior ao esperado (componente "nacional"). A estrutura industrial inicial dessa região não teve participação nesse crescimento. Isso ocorreu fundamentalmente pelo desempenho negativo da indústria madeireira, a maior especialização no ano de 1970, com taxa de crescimento de $-47,82 \%$ entre 1970 e 2000, bem diferente da macrorregião onde a taxa de crescimento desse mesmo setor foi de $23,34 \%$. 
Tabela 7 - Resultados do modelo estrutural-diferencial para a indústria da mesorregião Oeste Paranaense (1970/2000)

\begin{tabular}{|c|c|c|c|c|c|c|c|c|}
\hline Atividade do setor industrial & $\begin{array}{l}\text { PO } \\
1970\end{array}$ & $\begin{array}{l}\text { Comp. } \\
\text { "nac." }\end{array}$ & $\begin{array}{l}\text { Comp. } \\
\text { setorial }\end{array}$ & $\begin{array}{l}\text { Comp. } \\
\text { Difer. }\end{array}$ & $\begin{array}{c}\text { PO } \\
2000\end{array}$ & $\begin{array}{c}\text { Variação } \\
\text { total } \\
\text { absoluta }\end{array}$ & $\begin{array}{c}\text { Var. \% } \\
\text { no Sul/ } \\
\text { BR }\end{array}$ & $\begin{array}{c}\text { Variação } \\
\text { \% da } \\
\text { meso }\end{array}$ \\
\hline \multicolumn{9}{|l|}{ EXTRAÇÃO MINERAL } \\
\hline $\begin{array}{l}\text { Ext.e apar. de ped. e out. mat. } \\
\text { cons. }\end{array}$ & 117 & 249 & -260 & 387 & 494 & 377 & $-8,68$ & 322,22 \\
\hline Extração de petróleo e gás natural & 0 & 0 & 0 & 0 & 14 & 0 & 503,20 & 0,00 \\
\hline Extração de carvão-de-pedra & 15 & 32 & -40 & -7 & 0 & -15 & $-53,27$ & $-100,00$ \\
\hline $\begin{array}{l}\text { Exp. de salinas e fontes } \\
\text { hidrominerais }\end{array}$ & 0 & 0 & 0 & 0 & 8 & 0 & $1.184,21$ & 0,00 \\
\hline $\begin{array}{l}\text { Ext. e beneficiamento de outros } \\
\text { min. }\end{array}$ & 0 & 0 & 0 & 0 & 69 & 0 & 56,42 & 0,00 \\
\hline Faiscação e garimpagem & 0 & 0 & 0 & 0 & 0 & 0 & $-74,49$ & 0,00 \\
\hline \multicolumn{9}{|l|}{ IND. DE TRANSFORMAÇÃO } \\
\hline Ind. metalúrgica & 372 & 793 & 33 & 2.599 & 3.797 & 3.425 & 222,00 & 920,70 \\
\hline Ind. mecânica & 136 & 290 & 112 & 971 & 1.509 & 1.373 & 295,41 & $1.009,56$ \\
\hline Ind. de material elétrico e de com. & 18 & 38 & 71 & 359 & 487 & 469 & 608,75 & $2.605,56$ \\
\hline Ind. de material de transporte & 66 & 141 & 352 & 266 & 825 & 759 & 746,99 & $1.150,00$ \\
\hline Ind. de minerais não metálicos & 1.223 & 2.607 & -1.130 & 265 & 2.965 & 1.742 & 120,80 & 142,44 \\
\hline Ind. de borracha & 14 & 30 & 24 & 126 & 193 & 179 & 381,40 & $1.278,57$ \\
\hline Ind. de fumo & 18 & 38 & -17 & 53 & 93 & 75 & 119,86 & 416,67 \\
\hline Ind. de papel e papelão & 17 & 36 & -3 & 241 & 292 & 275 & 198,31 & $1.617,65$ \\
\hline Ind. de mobiliário & 861 & 1.835 & 272 & 2.445 & 5.413 & 4.552 & 244,77 & 528,69 \\
\hline Ind. de madeira & 6.041 & 12.878 & -11.468 & -4.299 & 3.152 & -2.889 & 23,34 & $-47,82$ \\
\hline $\begin{array}{l}\text { Ind. domiciliárias de artigos de } \\
\text { palha }\end{array}$ & 0 & 0 & 0 & 0 & 0 & 0 & $-21,61$ & 0,00 \\
\hline $\begin{array}{l}\text { Ind. de couro, peles e prod. } \\
\text { similares }\end{array}$ & 23 & 49 & -25 & 149 & 196 & 173 & 102,75 & 752,17 \\
\hline Ind. de materiais plásticos & 8 & 17 & 55 & 337 & 417 & 409 & 897,95 & $5.112,50$ \\
\hline Ind. de prod. der. do pet. e carvão & 3 & 6 & -4 & 25 & 31 & 28 & 96,40 & 933,33 \\
\hline Ind. têxtil & 82 & 175 & -55 & 795 & 997 & 915 & 146,22 & $1.115,85$ \\
\hline Ind. domiciliárias têxteis & 0 & 0 & 0 & 0 & 0 & 0 & $-95,08$ & 0,00 \\
\hline Ind. do vestuário & 16 & 34 & 244 & 4.952 & 5.246 & 5.230 & $1.736,72$ & $32.687,50$ \\
\hline Ind. dos calçados & 65 & 139 & 100 & 83 & 387 & 322 & 367,31 & 495,38 \\
\hline Ind. de bebidas e álcoois & 107 & 228 & -225 & 117 & 227 & 120 & 3,08 & 112,15 \\
\hline Ind. editorial e gráfica & 124 & 264 & 79 & 1.510 & 1.977 & 1.853 & 276,88 & $1.494,35$ \\
\hline Ind. de prod. farmac. e medicinais & 33 & 70 & 1 & 398 & 503 & 470 & 217,33 & $1.494,24$ \\
\hline Ind. química & 23 & 49 & 2 & 336 & 410 & 387 & 220,85 & $1.682,21$ \\
\hline Ind. de produtos alimentares & 1.517 & 3.234 & 337 & 10.813 & 15.900 & 14.383 & 235,36 & 948,12 \\
\hline $\begin{array}{l}\text { Outras classes da indústria de } \\
\text { transf. }\end{array}$ & 189 & 403 & 332 & 373 & 1.296 & 1.107 & 388,57 & 585,71 \\
\hline CONSTRUÇÃO CIVIL & 5.178 & 11.038 & -606 & 14.315 & 29.925 & 24.747 & 201,46 & 477,93 \\
\hline
\end{tabular}


conclusão...

\begin{tabular}{|c|c|c|c|c|c|c|c|c|}
\hline Atividade do setor industrial & $\begin{array}{c}\text { PO } \\
1970\end{array}$ & $\begin{array}{l}\text { Comp. } \\
\text { "nac." }\end{array}$ & $\begin{array}{l}\text { Comp. } \\
\text { setorial }\end{array}$ & $\begin{array}{l}\text { Comp. } \\
\text { Difer. }\end{array}$ & $\begin{array}{c}\text { PO } \\
2000\end{array}$ & $\begin{array}{c}\text { Variação } \\
\text { total } \\
\text { absoluta }\end{array}$ & $\begin{array}{c}\text { Var. \% } \\
\text { no Sul/ } \\
\text { BR }\end{array}$ & $\begin{array}{c}\text { Variação } \\
\text { \% da } \\
\text { meso }\end{array}$ \\
\hline \multicolumn{9}{|l|}{ SIUP } \\
\hline $\begin{array}{l}\text { Prod. e dist. de energia elétrica e } \\
\text { gás }\end{array}$ & 124 & 264 & -181 & 2.586 & 2.793 & 2.669 & 66,93 & $2.152,42$ \\
\hline Abast. de água e serviço de esgoto & 26 & 55 & 65 & 1.632 & 1.778 & 1.752 & 463,08 & $6.738,46$ \\
\hline TOTAL DA INDÚSTRIA & 16.416 & 34.994 & -11.934 & 41.827 & 81.394 & 64.887 & 213,17 & 395,82 \\
\hline
\end{tabular}

Fonte: Elaborada pelos autores a partir de Instituto Brasileiro de Geografia e Estatística (2005, 2002).

O componente diferencial elevado mostra que essa mesorregião soube aproveitar suas vantagens competitivas do setor industrial. Os setores que mais contribuíram nessa performance, ou seja, que apresentaram melhores vantagens competitivas, foram da construção civil, das indústrias de produtos alimentares e da indústria do vestuário. As indústrias de produtos alimentares eram uma das especializações em 2000. Os setores dos serviços industriais de utilidade pública juntamente com as indústrias de produtos farmacêuticos e veterinários completavam o rol de especializações nesse ano. Esse grupo de setores também contribuiu no desempenho da mesorregião com taxas acima da média "nacional". Deve-se destacar que o crescimento na população ocupada dos serviços industriais de utilidade pública (especializações com alto valores absolutos de QL), no Oeste Paranaense, esteve diretamente relacionado com a construção da Usina Hidrelétrica de Itaipu concretizada na década de 1980, sendo a sede da Usina localizada no município de Foz do Iguaçu.

Conforme mostra a variação total absoluta, um dos setores que mais contribuiu no desempenho mesorregional foi o setor das indústrias de produtos alimentares. Essa mesorregião tem uma particularidade apontada por Instituto de Pesquisa Econômica Aplicada (2000): a ação cooperativada da economia local especializada na produção de aves e suínos, e também no leite, com alto nível tecnológico e forte integração agroindustrial. Cerca de $50 \%$ dos produtores cooperativados do Estado do Paraná, em 1996, estavam localizados e distribuídos pela maioria dos municípios do Oeste Paranaense.

No geral, todos os setores, com exceção da indústria madeireira, apresentaram taxas de crescimento significativas e superiores as apresentadas, nos mesmos setores no Sul do Brasil. O comportamento do conjunto desses setores, e em especial das indústrias de produtos alimentares e da construção civil, proporcionaram o desempenho positivo do setor industrial no Oeste Paranaense.

A diferença entre a variação total absoluta e o componente nacional mostra que o melhor desempenho industrial foi da mesorregião Oeste Paranaense, que apresentou um incremento de pessoas ocupadas 1,85 vezes maior do que o esperado, seguido do Oeste Catarinense, onde esse desempenho foi de 1,61 vezes. 


\section{Dinamismos do Setor de Serviços entre 1970 e 2000}

O setor de serviços dessas mesorregiões foi influenciado tanto pelo aumento populacional ocorrido no período 1970-2000 e da crescente urbanização, como pelos efeitos de encadeamentos do desenvolvimento dos setores primário e secundário.

Conforme a Tabela 8, o setor de serviços do Oeste Catarinense passou de um total de 41.863 pessoas ocupadas, em 1970, para 236.005 em 2000, ou seja, $463,76 \%$ de crescimento, bem superior ao da macrorregião. A estrutura de serviços do Oeste Catarinense era uma das mais diversificadas (multiespecializada) em 1970, mesmo assim essa estrutura não foi responsável pelo desempenho mesorregional, confirmado pelo saldo negativo do componente setorial. Por um lado, sua estrutura inicial do setor de serviços era restrita a poucas atividades. Por outro, o desenvolvimento dos setores agropecuário e industrial, além da urbanização ocorrida no período exigiu que outros setores se desenvolvessem, principalmente aqueles ligados diretamente à prestação de serviços das agroindústrias da mesorregião e ao processo de comercialização por elas comandado. Isso é comprovando pelo aumento no número de especializações, passando de 18 para 21 no período.

O saldo do componente diferencial dessa mesorregião foi positivo e elevado (99.507 PO). Vantagens competitivas, principalmente dos subsetores do comércio de mercadorias, da prestação de serviços e dos transportes, comunicação e armazenagem, explicaram o desempenho positivo do setor terciário da mesorregião catarinense. A grande maioria das atividades terciárias dessa mesorregião apresentou taxas de crescimento superiores se comparadas aos mesmos setores do Sul do Brasil. Assim, suas especializações se deram em setores de grande dinamismo.

Essa mesorregião consolidou-se na especialização das atividades de aves e suínos no período 1970-2000, e o desempenho positivo apresentado por essas atividades, nesse lapso de tempo, e os efeitos de encadeamento surgidos a partir dele foram a base do desempenho dos três macrossetores analisados do Oeste Catarinense.

Tabela 8 - Resultados do modelo estrutural-diferencial para o setor de serviços da mesorregião Oeste Catarinense (1970 e 2000)

\begin{tabular}{|c|c|c|c|c|c|c|c|c|}
\hline Atividade do setor de serviços & $\begin{array}{c}\text { PO } \\
1970\end{array}$ & $\begin{array}{l}\text { Comp. } \\
\text { "nac." }\end{array}$ & $\begin{array}{l}\text { Comp. } \\
\text { setorial }\end{array}$ & $\begin{array}{l}\text { Comp. } \\
\text { Difer. }\end{array}$ & $\begin{array}{c}\text { PO } \\
2000\end{array}$ & $\begin{array}{l}\text { Var. } \\
\text { total } \\
\text { absol. }\end{array}$ & $\begin{array}{l}\text { Var. \% } \\
\text { Sul do } \\
\text { Brasil }\end{array}$ & $\begin{array}{l}\text { Var. \% da } \\
\text { meso }\end{array}$ \\
\hline \multicolumn{9}{|l|}{ Comércio de mercadorias } \\
\hline $\begin{array}{l}\text { Comércio de produtos } \\
\text { agropecuários e extrativos }\end{array}$ & 165 & 455 & 171 & 792 & 1.583 & 1.418 & 379,65 & 859,39 \\
\hline $\begin{array}{l}\text { Comércio de gêneros } \\
\text { alimentícios, bebidas e } \\
\text { estimulantes }\end{array}$ & 3.581 & 9.884 & -6.244 & 8.528 & 15.749 & 12.168 & 101,63 & 339,79 \\
\hline
\end{tabular}




\begin{tabular}{|c|c|c|c|c|c|c|c|c|}
\hline Atividade do setor de serviços & $\begin{array}{l}\text { PO } \\
1970\end{array}$ & $\begin{array}{l}\text { Comp. } \\
\text { "nac." }\end{array}$ & $\begin{array}{l}\text { Comp. } \\
\text { setorial }\end{array}$ & $\begin{array}{l}\text { Comp. } \\
\text { Difer. }\end{array}$ & $\begin{array}{c}\text { PO } \\
2000\end{array}$ & $\begin{array}{c}\text { Var. } \\
\text { total } \\
\text { absol. }\end{array}$ & $\begin{array}{l}\text { Var. \% } \\
\text { Sul do } \\
\text { Brasil }\end{array}$ & $\begin{array}{l}\text { Var. \% da } \\
\text { meso }\end{array}$ \\
\hline \multicolumn{9}{|l|}{ Comércio de mercadorias } \\
\hline $\begin{array}{l}\text { Com. de tecidos e art. de tecidos, } \\
\text { art. do vest. e armarinho }\end{array}$ & 1.563 & 4.314 & -2.307 & 2.062 & 5.632 & 4.069 & 128,43 & 260,33 \\
\hline $\begin{array}{l}\text { Comércio de móveis, tapeçarias, } \\
\text { objetos de arte e ornament. }\end{array}$ & 28 & 77 & 17 & 768 & 891 & 863 & 337,78 & $3.082,14$ \\
\hline $\begin{array}{l}\text { Comércio de papel, impressos e } \\
\text { artigos de escritório }\end{array}$ & 61 & 168 & -31 & 681 & 880 & 819 & 225,63 & $1.342,62$ \\
\hline $\begin{array}{l}\text { Comércio de ferragens, louças, } \\
\text { mat. de const. e prod. metal. }\end{array}$ & 262 & 723 & 641 & 2.384 & 4.010 & 3.748 & 520,58 & $1.430,53$ \\
\hline $\begin{array}{l}\text { Comércio de máquinas, aparelhos, } \\
\text { inst., etc. }\end{array}$ & 377 & 1.041 & 654 & 3.615 & 5.686 & 5.309 & 449,39 & $1.408,22$ \\
\hline $\begin{array}{l}\text { Comércio de combustíveis e } \\
\text { lubrificantes }\end{array}$ & 462 & 1.275 & 255 & 1.289 & 3.281 & 2.819 & 331,23 & 610,17 \\
\hline Feiras e mercados & 17 & 47 & 457 & 1.427 & 1.948 & 1.931 & $2.962,66$ & $11.358,82$ \\
\hline $\begin{array}{l}\text { Outras atividades do comércio de } \\
\text { mercadorias }\end{array}$ & 2.390 & 6.596 & 2.183 & 714 & 11.883 & 9.493 & 367,33 & 397,20 \\
\hline \multicolumn{9}{|l|}{ Prestação de serviços } \\
\hline Serviço de alojamento & 954 & 2.633 & -1.238 & -870 & 1.479 & 525 & 146,23 & 55,03 \\
\hline Serviço de alimentação & 460 & 1.270 & 5.497 & 3.068 & 10.294 & 9.834 & $1.470,93$ & $2.137,83$ \\
\hline Serviço de higiene pessoal & 1.527 & 4.215 & -2.805 & 1.626 & 4.562 & 3.035 & 92,29 & 198,76 \\
\hline $\begin{array}{l}\text { Serv. de confec. sob medida, } \\
\text { cons. e rep. de artigos do vest. }\end{array}$ & 2.093 & 5.777 & -6.771 & -560 & 539 & -1.554 & $-47,50$ & $-74,25$ \\
\hline $\begin{array}{l}\text { Serviços de cons., reparação e } \\
\text { inst. de máquinas e veículos }\end{array}$ & 502 & 1.386 & 3.577 & 3.226 & 8.691 & 8.189 & 988,60 & $1.631,27$ \\
\hline $\begin{array}{l}\text { Serviços de conservação de } \\
\text { edifícios }\end{array}$ & 498 & 1.374 & -1.088 & 280 & 1.064 & 566 & 57,49 & 113,65 \\
\hline Serviços domésticos & 26 & 72 & 3.434 & 31.360 & 34.891 & 34.865 & $13.482,46$ & $134.096,15$ \\
\hline $\begin{array}{l}\text { Outras classes da prestação de } \\
\text { serviços }\end{array}$ & 5.555 & 15.332 & -18.720 & 1.384 & 3.551 & -2.004 & $-60,09$ & $-36,08$ \\
\hline \multicolumn{9}{|c|}{ Transportes, comunicações e armazenagem } \\
\hline $\begin{array}{l}\text { Transportes à tração e condução } \\
\text { animal }\end{array}$ & 132 & 364 & -431 & -60 & 5 & -127 & $-50,59$ & $-96,21$ \\
\hline Transportes rodoviários & 4.016 & 11.084 & -2.895 & 8.869 & 21.074 & 17.058 & 203,91 & 424,75 \\
\hline Transportes ferroviários & 446 & 1.231 & -1.594 & -78 & 5 & -441 & $-81,44$ & $-98,88$ \\
\hline $\begin{array}{l}\text { Transportes marítimos, fluviais e } \\
\text { lacustres }\end{array}$ & 27 & 75 & -79 & 9 & 32 & 5 & $-15,69$ & 18,52 \\
\hline Transportes aéreos & 12 & 33 & -19 & 15 & 41 & 29 & 114,29 & 241,67 \\
\hline $\begin{array}{l}\text { Serviços postais, telegráficos e de } \\
\text { radiocomunicações }\end{array}$ & 198 & 546 & -422 & -12 & 311 & 113 & 62,90 & 57,07 \\
\hline Telefones & 81 & 224 & 242 & 122 & 668 & 587 & 574,52 & 724,69 \\
\hline Armazenagem & 62 & 171 & -155 & 104 & 182 & 120 & 26,01 & 193,55 \\
\hline $\begin{array}{l}\text { Outras classes de transportes, } \\
\text { comunicações e armazenagem }\end{array}$ & 20 & 55 & 175 & 4.876 & 5.126 & 5.106 & $1.152,13$ & $25.530,00$ \\
\hline
\end{tabular}




\begin{tabular}{|c|c|c|c|c|c|c|c|c|}
\hline Atividade do setor de serviços & $\begin{array}{c}\text { PO } \\
1970\end{array}$ & $\begin{array}{l}\text { Comp. } \\
\text { "nac." }\end{array}$ & $\begin{array}{l}\text { Comp. } \\
\text { setorial }\end{array}$ & $\begin{array}{l}\text { Comp. } \\
\text { Difer. }\end{array}$ & $\begin{array}{c}\text { PO } \\
2000\end{array}$ & $\begin{array}{c}\text { Var. } \\
\text { total } \\
\text { absol. }\end{array}$ & $\begin{array}{l}\text { Var. \% } \\
\text { Sul do } \\
\text { Brasil }\end{array}$ & $\begin{array}{l}\text { Var. \% da } \\
\text { meso }\end{array}$ \\
\hline \multicolumn{9}{|l|}{ Atividades sociais } \\
\hline Ensino público & 5.505 & 15.194 & -9.470 & 330 & 11.559 & 6.054 & 103,98 & 109,97 \\
\hline Ensino particular & 385 & 1.063 & 2.645 & 6.184 & 10.276 & 9.891 & 962,94 & $2.569,09$ \\
\hline Previdência social & 56 & 155 & -147 & 303 & 367 & 311 & 13,99 & 555,36 \\
\hline Assistência e beneficiência & 25 & 69 & 141 & 984 & 1.219 & 1.194 & 838,14 & $4.776,00$ \\
\hline Sindicatos e associações de classe & 30 & 83 & 0 & 184 & 297 & 267 & 275,80 & 890,00 \\
\hline $\begin{array}{l}\text { Assistência médico-hospitalar } \\
\text { pública }\end{array}$ & 80 & 221 & 163 & 1.274 & 1.738 & 1.658 & 479,98 & $2.072,50$ \\
\hline $\begin{array}{l}\text { Assistência médico-hospitalar } \\
\text { particular }\end{array}$ & 699 & 1.929 & 1.992 & 346 & 4.966 & 4.267 & 560,96 & 610,44 \\
\hline Advocacia e atividades auxiliares & 69 & 190 & 636 & 609 & 1.505 & 1.436 & $1.198,12$ & $2.081,16$ \\
\hline $\begin{array}{l}\text { Engenharia, arquitetura e } \\
\text { atividades auxiliares }\end{array}$ & 62 & 171 & 301 & -189 & 345 & 283 & 761,65 & 456,45 \\
\hline $\begin{array}{l}\text { Odontologia e atividades } \\
\text { auxiliares }\end{array}$ & 266 & 734 & 76 & -75 & 1.001 & 735 & 304,41 & 276,32 \\
\hline $\begin{array}{l}\text { Agronomia, veterinária e } \\
\text { atividades auxiliares }\end{array}$ & 42 & 116 & 158 & -142 & 174 & 132 & 652,98 & 314,29 \\
\hline $\begin{array}{l}\text { Contabilidade e atividades } \\
\text { auxiliares }\end{array}$ & 914 & 2.523 & -897 & -199 & 2.340 & 1.426 & 177,84 & 156,02 \\
\hline Outras atividades sociais & 782 & 2.158 & 698 & 251 & 3.889 & 3.107 & 365,25 & 397,31 \\
\hline \multicolumn{9}{|c|}{ Serviços administrativos governamentais, legislativo, justiça } \\
\hline Poder legislativo & 7 & 19 & 24 & 163 & 214 & 207 & 624,80 & $2.957,14$ \\
\hline Justiça e atividades auxiliares & 385 & 1.063 & -73 & -180 & 1.195 & 810 & 257,04 & 210,39 \\
\hline Serviço administrativo federal & 253 & 698 & -383 & 456 & 1.024 & 771 & 124,51 & 304,74 \\
\hline Serviço administrativo estadual & 369 & 1.018 & -551 & 672 & 1.508 & 1.139 & 126,62 & 308,67 \\
\hline Serviço administrativo municipal & 735 & 2.029 & 2.862 & 4.693 & 10.318 & 9.583 & 665,37 & $1.303,81$ \\
\hline $\begin{array}{l}\text { Outras classes e classe mal } \\
\text { definida }\end{array}$ & 1.083 & 2.989 & -3.288 & -704 & 80 & -1.003 & $-27,60$ & $-92,61$ \\
\hline \multicolumn{9}{|c|}{ Defesa nacional e segurança pública } \\
\hline Exército & 215 & 593 & -582 & 476 & 702 & 487 & 5,17 & 226,51 \\
\hline Marinha de guerra & 0 & 0 & 0 & 0 & 0 & 0 & 56,93 & 0,00 \\
\hline Aeronáutica & 3 & 8 & -8 & -3 & 0 & -3 & 6,11 & $-100,00$ \\
\hline Polícia militar & 410 & 1.132 & -983 & 1.032 & 1.590 & 1.180 & 36,14 & 287,80 \\
\hline Polícia civil & 139 & 384 & -187 & 256 & 592 & 453 & 141,66 & 325,90 \\
\hline Corpo de bombeiros & 46 & 127 & -32 & 49 & 190 & 144 & 206,91 & 313,04 \\
\hline Outras organizações de segurança & 119 & 328 & -301 & 308 & 454 & 335 & 22,76 & 281,51 \\
\hline \multicolumn{9}{|c|}{ Comércio de imóveis e valores mobiliários, créditos, seguros e capitalização } \\
\hline Comércio de imóveis & 46 & 127 & 34 & 438 & 645 & 599 & 349,40 & $1.302,17$ \\
\hline Comércio de títulos e moedas & 20 & 55 & -70 & 1 & 6 & -14 & $-74,66$ & $-70,00$ \\
\hline Bancos e casas bancárias & 744 & 2.053 & -1.110 & 846 & 2.533 & 1.789 & 126,79 & 240,46 \\
\hline $\begin{array}{l}\text { Caixas econômicas e cooperativas } \\
\text { de crédito }\end{array}$ & 21 & 58 & -71 & 59 & 67 & 46 & $-63,41$ & 219,05 \\
\hline
\end{tabular}


conclusão...

\begin{tabular}{|c|c|c|c|c|c|c|c|c|}
\hline Atividade do setor industrial & $\begin{array}{l}\text { PO } \\
1970\end{array}$ & $\begin{array}{l}\text { Comp. } \\
\text { "nac." }\end{array}$ & $\begin{array}{l}\text { Comp. } \\
\text { setorial }\end{array}$ & $\begin{array}{l}\text { Comp. } \\
\text { Difer. }\end{array}$ & $\begin{array}{c}\text { PO } \\
2000\end{array}$ & $\begin{array}{l}\text { Var. } \\
\text { total } \\
\text { absol. }\end{array}$ & $\begin{array}{l}\text { Var. \% } \\
\text { Sul do } \\
\text { Brasil }\end{array}$ & $\begin{array}{l}\text { Var. } \% \\
\text { da meso }\end{array}$ \\
\hline \multicolumn{9}{|c|}{ Comércio de imóveis e valores mobiliários, créditos, seguros e capitalização } \\
\hline Seguros e capitalização & 35 & 97 & 11 & 262 & 404 & 369 & 306,63 & $1.054,29$ \\
\hline $\begin{array}{l}\text { Outras atividades do comércio de } \\
\text { imóveis }\end{array}$ & 10 & 28 & -14 & -1 & 23 & 13 & 135,63 & 130,00 \\
\hline Outras Atividades & 2.793 & 7.709 & 15.018 & 5.207 & 30.726 & 27.933 & 813,69 & $1.000,11$ \\
\hline SETOR SECUNDÁRIO & 41.863 & 115.543 & -20.908 & 99.507 & 236.005 & 194.142 & 276,00 & 463,76 \\
\hline
\end{tabular}

Fonte: Elaborada pelos autores a partir de Instituto Brasileiro de Geografia e Estatística (2002).

A mesorregião Oeste Paranaense foi a que apresentou o maior crescimento no número de pessoas ocupadas do setor terciário, com 691,85\%, passando de 39.546, em 1970, para 313.145 em 2000 (Tabela 9). Essa mesorregião apresentou o maior valor absoluto no saldo da componente diferencial, onde a maioria das atividades apresentou valores positivos nesse componente. Partindo de uma estrutura de serviços pouco favorável, essa mesorregião se especializou em setores competitivos.

Tabela 9 - Resultados do modelo estrutural-diferencial para o setor de serviços da mesorregião Oeste Paranaense (1970 e 2000)

\begin{tabular}{|c|c|c|c|c|c|c|c|c|}
\hline Atividade do setor de serviços & $\begin{array}{l}\text { PO } \\
1970\end{array}$ & $\begin{array}{l}\text { Comp. } \\
\text { "nac." }\end{array}$ & $\begin{array}{l}\text { Comp. } \\
\text { setorial }\end{array}$ & $\begin{array}{l}\text { Comp. } \\
\text { Difer. }\end{array}$ & $\begin{array}{c}\text { PO } \\
2000\end{array}$ & $\begin{array}{l}\text { Var. } \\
\text { total } \\
\text { absol. }\end{array}$ & $\begin{array}{l}\text { Var. \% } \\
\text { Sul do } \\
\text { Brasil }\end{array}$ & $\begin{array}{l}\text { Var. \% da } \\
\text { meso }\end{array}$ \\
\hline \multicolumn{9}{|l|}{ Comércio de mercadorias } \\
\hline $\begin{array}{l}\text { Comércio de produtos } \\
\text { agropecuários e extrativos }\end{array}$ & 378 & 1.043 & 392 & 1.135 & 2.948 & 2.570 & 379,65 & 679,89 \\
\hline $\begin{array}{l}\text { Comércio de gêneros } \\
\text { alimentícios, bebidas e } \\
\text { estimulantes }\end{array}$ & 5.619 & 15.509 & -9.798 & 4.528 & 15.858 & 10.239 & 101,63 & 182,22 \\
\hline $\begin{array}{l}\text { Com. de tecidos e art. de tecidos, } \\
\text { art. do vest. e armarinho }\end{array}$ & 1.507 & 4.159 & -2.224 & 3.808 & 7.250 & 5.743 & 128,43 & 381,09 \\
\hline $\begin{array}{l}\text { Comércio de móveis, tapeçarias, } \\
\text { objetos de arte e ornament. }\end{array}$ & 51 & 141 & 32 & 1.373 & 1.596 & 1.545 & 337,78 & $3.029,41$ \\
\hline $\begin{array}{l}\text { Comércio de papel, impressos e } \\
\text { artigos de escritório }\end{array}$ & 113 & 312 & -57 & 826 & 1.194 & 1.081 & 225,63 & 956,64 \\
\hline $\begin{array}{l}\text { Comércio de ferragens, louças, } \\
\text { mat. de const. e prod. metal. }\end{array}$ & 305 & 842 & 746 & 3.697 & 5.590 & 5.285 & 520,58 & $1.732,79$ \\
\hline $\begin{array}{l}\text { Comércio de máquinas, aparelhos, } \\
\text { inst., etc. }\end{array}$ & 534 & 1.474 & 926 & 7.121 & 10.055 & 9.521 & 449,39 & $1.782,96$ \\
\hline $\begin{array}{l}\text { Comércio de combustíveis e } \\
\text { lubrificantes }\end{array}$ & 574 & 1.584 & 317 & 2.189 & 4.664 & 4.090 & 331,23 & 712,54 \\
\hline Feiras e mercados & 14 & 39 & 376 & 2.976 & 3.405 & 3.391 & $2.962,66$ & $24.221,43$ \\
\hline $\begin{array}{l}\text { Outras atividades do comércio de } \\
\text { mercadorias }\end{array}$ & 2.597 & 7.168 & 2.372 & 16.536 & 28.673 & 26.076 & 367,33 & $1.004,08$ \\
\hline \multicolumn{9}{|l|}{ Prestação de serviços } \\
\hline Serviço de alojamento & 908 & 2.506 & -1.178 & 2.518 & 4.754 & 3.846 & 146,23 & 423,57 \\
\hline Serviço de alimentação & 416 & 1.148 & 4.971 & 8.636 & 15.171 & 14.755 & $1.470,93$ & $3.546,88$ \\
\hline
\end{tabular}

ALVES, L. R.; PAIVA, C. A. N. Determinantes do desempenho econômico das mesorregiões... 


\begin{tabular}{|c|c|c|c|c|c|c|c|c|}
\hline Atividade do setor de serviços & $\begin{array}{l}\text { PO } \\
1970\end{array}$ & $\begin{array}{l}\text { Comp. } \\
\text { "nac." }\end{array}$ & $\begin{array}{l}\text { Comp. } \\
\text { setorial }\end{array}$ & $\begin{array}{l}\text { Comp. } \\
\text { Difer. }\end{array}$ & $\begin{array}{c}\text { PO } \\
2000\end{array}$ & $\begin{array}{c}\text { Var. } \\
\text { total } \\
\text { absol. }\end{array}$ & $\begin{array}{c}\text { Var. \% } \\
\text { Sul do } \\
\text { Brasil }\end{array}$ & $\begin{array}{l}\text { Var. \% da } \\
\text { meso }\end{array}$ \\
\hline \multicolumn{9}{|l|}{ Prestação de serviços } \\
\hline Serviço de higiene pessoal & 1.606 & 4.433 & -2.950 & 3.131 & 6.219 & 4.613 & 92,29 & 287,24 \\
\hline $\begin{array}{l}\text { Serv. de confec. sob medida, } \\
\text { cons. e rep. de artigos do vest. }\end{array}$ & 1.998 & 5.515 & -6.464 & 2.638 & 3.687 & 1.689 & $-47,50$ & 84,53 \\
\hline $\begin{array}{l}\text { Serviços de cons., reparação e } \\
\text { inst. de máquinas e veículos }\end{array}$ & 368 & 1.016 & 2.622 & 7.190 & 11.196 & 10.828 & 988,60 & $2.942,39$ \\
\hline $\begin{array}{l}\text { Serviços de conservação de } \\
\text { edifícios }\end{array}$ & 561 & 1.548 & -1.226 & 735 & 1.619 & 1.058 & 57,49 & 188,59 \\
\hline Serviços domésticos & 34 & 94 & 4.490 & 40.817 & 45.435 & 45.401 & $13.482,46$ & $133.532,35$ \\
\hline $\begin{array}{l}\text { Outras classes da prestação de } \\
\text { serviços }\end{array}$ & 4.555 & 12.572 & -15.350 & 2.735 & 4.512 & -43 & $-60,99$ & $-0,94$ \\
\hline \multicolumn{9}{|c|}{ Transportes, comunicações e armazenagem } \\
\hline $\begin{array}{l}\text { Transportes à tração e condução } \\
\text { animal }\end{array}$ & 97 & 268 & -317 & 1.062 & 1.110 & 1.013 & $-50,59$ & $1.044,33$ \\
\hline Transportes rodoviários & 4.210 & 11.628 & -3.035 & 9.317 & 22.112 & 17.902 & 203,91 & 425,23 \\
\hline Transportes ferroviários & 39 & 108 & -139 & 18 & 25 & -14 & $-81,44$ & $-35,90$ \\
\hline $\begin{array}{l}\text { Transportes marítimos, fluviais e } \\
\text { lacustres }\end{array}$ & 106 & 293 & -309 & -33 & 56 & -50 & $-15,69$ & $-47,17$ \\
\hline Transportes aéreos & 32 & 88 & -52 & 84 & 153 & 121 & 114,29 & 378,13 \\
\hline $\begin{array}{l}\text { Serviços postais, telegráficos e de } \\
\text { radiocomunicações }\end{array}$ & 97 & 268 & -207 & 288 & 446 & 349 & 62,90 & 359,79 \\
\hline Telefones & 60 & 166 & 179 & 1.317 & 1.722 & 1.662 & 574,52 & $2.770,00$ \\
\hline Armazenagem & 63 & 174 & -157 & 92 & 171 & 108 & 26,01 & 171,43 \\
\hline $\begin{array}{l}\text { Outras classes de transportes, } \\
\text { comunicações e armazenagem }\end{array}$ & 72 & 199 & 631 & 6.370 & 7.272 & 7.200 & $1.152,13$ & $10.000,00$ \\
\hline \multicolumn{9}{|l|}{ Atividades sociais } \\
\hline Ensino público & 3.305 & 9.122 & -5.685 & 8.128 & 14.870 & 11.565 & 103,98 & 349,92 \\
\hline Ensino particular & 447 & 1.234 & 3.071 & 4.811 & 9.562 & 9.115 & 962,94 & $2.039,15$ \\
\hline Previdência social & 36 & 99 & -94 & 218 & 259 & 223 & 13,99 & 619,44 \\
\hline Assistência e beneficiência & 3 & 8 & 17 & 2.057 & 2.085 & 2.082 & 838,14 & $69.400,00$ \\
\hline Sindicatos e associações de classe & 22 & 61 & 0 & 264 & 347 & 325 & 275,80 & $1.477,27$ \\
\hline $\begin{array}{l}\text { Assistência médico-hospitalar } \\
\text { pública }\end{array}$ & 90 & 248 & 184 & 1.579 & 2.101 & 2.011 & 479,98 & $2.234,44$ \\
\hline $\begin{array}{l}\text { Assistência médico-hospitalar } \\
\text { particular }\end{array}$ & 317 & 875 & 903 & 3.447 & 5.542 & 5.225 & 560,96 & $1.648,26$ \\
\hline Advocacia e atividades auxiliares & 99 & 273 & 913 & 485 & 1.770 & 1.671 & $1.198,12$ & $1.687,88$ \\
\hline $\begin{array}{l}\text { Engenharia, arquitetura e } \\
\text { atividades auxiliares }\end{array}$ & 77 & 213 & 374 & -98 & 565 & 488 & 761,65 & 633,77 \\
\hline $\begin{array}{l}\text { Odontologia e atividades } \\
\text { auxiliares }\end{array}$ & 156 & 431 & 44 & 759 & 1.390 & 1.234 & 304,41 & 791,03 \\
\hline $\begin{array}{l}\text { Agronomia, veterinária e } \\
\text { atividades auxiliares }\end{array}$ & 26 & 72 & 98 & -23 & 173 & 147 & 652,98 & 565,38 \\
\hline
\end{tabular}


conclusão...

\begin{tabular}{|c|c|c|c|c|c|c|c|c|}
\hline Atividade do setor de serviços & $\begin{array}{c}\text { PO } \\
1970\end{array}$ & $\begin{array}{l}\text { Comp. } \\
\text { "nac." }\end{array}$ & $\begin{array}{l}\text { Comp. } \\
\text { setorial }\end{array}$ & $\begin{array}{l}\text { Comp. } \\
\text { Difer. }\end{array}$ & $\begin{array}{c}\text { PO } \\
2000\end{array}$ & $\begin{array}{l}\text { Var. } \\
\text { total } \\
\text { absol. }\end{array}$ & $\begin{array}{l}\text { Var. \% } \\
\text { Sul do } \\
\text { Brasil }\end{array}$ & $\begin{array}{l}\text { Var. \% } \\
\text { da meso }\end{array}$ \\
\hline $\begin{array}{l}\text { Contabilidade e atividades } \\
\text { auxiliares }\end{array}$ & 1.065 & 2.939 & -1.045 & -220 & 2.739 & 1.674 & 177,84 & 157,18 \\
\hline Outras atividades sociais & 599 & 1.653 & 535 & 3.003 & 5.790 & 5.191 & 365,25 & 866,61 \\
\hline \multicolumn{9}{|c|}{ Serviços administrativos governamentais, legislativo, justiça } \\
\hline Poder legislativo & 11 & 30 & 38 & 372 & 452 & 441 & 624,80 & $4.009,09$ \\
\hline Justiça e atividades auxiliares & 207 & 571 & -39 & 967 & 1.706 & 1.499 & 257,04 & 724,15 \\
\hline Serviço administrativo federal & 246 & 679 & -373 & 520 & 1.072 & 826 & 124,51 & 335,77 \\
\hline Serviço administrativo estadual & 169 & 466 & -252 & 1.336 & 1.719 & 1.550 & 126,62 & 917,16 \\
\hline Serviço administrativo municipal & 513 & 1.416 & 1.997 & 7.772 & 11.698 & 11.185 & 665,37 & $2.180,31$ \\
\hline $\begin{array}{l}\text { Outras classes e classe mal } \\
\text { definida }\end{array}$ & 548 & 1.512 & -1.664 & -397 & 0 & -548 & $-27,60$ & $-100,00$ \\
\hline \multicolumn{9}{|c|}{ Defesa nacional e segurança pública } \\
\hline Exército & 851 & 2.349 & -2.305 & 864 & 1.759 & 908 & 5,17 & 106,70 \\
\hline Marinha de guerra & 38 & 105 & -83 & 32 & 92 & 54 & 56,93 & 142,11 \\
\hline Aeronáutica & 57 & 157 & -154 & 20 & 80 & 23 & 6,11 & 40,35 \\
\hline Polícia militar & 175 & 483 & -420 & 831 & 1.069 & 894 & 36,14 & 510,86 \\
\hline Polícia civil & 308 & 850 & -414 & 443 & 1.187 & 879 & 141,66 & 285,39 \\
\hline Corpo de bombeiros & 0 & 0 & 0 & 0 & 140 & 0 & 206,91 & 0,00 \\
\hline Outras organizações de segurança & 89 & 246 & -225 & -96 & 13 & -76 & 22,76 & $-85,39$ \\
\hline \multicolumn{9}{|c|}{ Comércio de imóveis e valores mobiliários, créditos, seguros e capitalização } \\
\hline Comércio de imóveis & 171 & 472 & 126 & 267 & 1.035 & 864 & 349,40 & 505,26 \\
\hline Comércio de títulos e moedas & 4 & 11 & -14 & 67 & 68 & 64 & $-74,66$ & $1.600,00$ \\
\hline Bancos e casas bancárias & 577 & 1.593 & -861 & 1.440 & 2.749 & 2.172 & 126,79 & 376,43 \\
\hline $\begin{array}{l}\text { Caixas econômicas e cooperativas } \\
\text { de crédito }\end{array}$ & 4 & 11 & -14 & 42 & 43 & 39 & $-63,41$ & 975,00 \\
\hline Seguros e capitalização & 28 & 77 & 9 & 645 & 759 & 731 & 306,63 & $2.610,71$ \\
\hline $\begin{array}{l}\text { Outras atividades do comércio de } \\
\text { imóveis }\end{array}$ & 13 & 36 & -18 & 137 & 168 & 155 & 135,63 & $1.192,31$ \\
\hline Outras atividades & 2.381 & 6.572 & 12.802 & 11.495 & 33.250 & 30.869 & 813,69 & $1.296,47$ \\
\hline SETOR SECUNDÁRIO & 39.546 & 109.148 & -17.960 & 182.271 & 313.145 & 273.459 & 276,00 & 691,85 \\
\hline
\end{tabular}

Fonte: Elaborada pelos autores a partir de Instituto Brasileiro de Geografia e Estatística (2002).

Todas as atividades do comércio de mercadorias, da prestação de serviços, do comércio de imóveis e a grande maioria das demais apresentaram taxas de crescimento bem superiores às apresentadas pelos mesmos setores no Sul do Brasil. Isso explica, em parte, o aumento do número de especializações em 2000 nessa mesorregião. É impressionante o desempenho do setor terciário dessa mesorregião no período 1970-2000. Foi a mesorregião que apresentou melhores vantagens competitivas no setor terciário, entre as mesorregiões analisadas, fato confirmado pelo saldo positivo e significativamente elevado do componente diferencial, que foi de 182.271 PO, superior as 99.507 PO do Oeste Catarinense. 
Mesmo tendo se consolidado na especialização da cultura da soja, o desempenho crescente e positivo das atividades de aves e suínos do Oeste Paranaense deu a essa mesorregião uma performance distinta. As indústrias de produtos alimentares ligadas aos segmentos da soja, milho, aves e suínos estão na base desse desempenho. Além disso, não se pode esquecer a influência causada pela construção de Itaipu, bem como pelo desenvolvimento do turismocomercial dos municípios lindeiros ao lago de Itaipu, e é claro, pelo polo turístico de Foz do Iguaçu, devido à existência do Parque Nacional do Iguaçu, das Cataratas e de Itaipu, sem contar que esse município é centro comercial de fronteira. Essas características dão a essa mesorregião particularidades no seu desenvolvimento socioeconômico.

Assim, no geral, as duas mesorregiões em análise partiram de uma estrutura de serviços limitada e apresentaram desempenhos significativos devido às suas capacidades competitivas, especializando-se em setores dinâmicos que apresentaram altas taxas de crescimento no período 1970-2000. O Oeste Paranaense foi a mesorregião que mais excedeu o esperado de crescimento (variação total absoluta / componente "nacional"), cerca de 2,51 vezes a mais que o esperado. No Oeste Catarinense, esse número foi de 1,68 vezes.

Assim, a Tabela 10 apresenta os resultados do coeficiente de reestruturação para as mesorregiões em análise.

Tabela 10 - Coeficiente de reestruturação das mesorregiões Oeste Catarinense e Oeste Paranaense (1970/2000)

\begin{tabular}{ccc}
\hline Setor & Oeste Catarinense & Oeste Paranaense \\
\hline Agropecuária & 0,3282 & 0,4015 \\
Indústria & 0,3205 & 0,3730 \\
Serviços & 0,4186 & 0,4283 \\
\hline
\end{tabular}

Fonte: Elaborada pelos autores a partir dos resultados da pesquisa.

Percebe-se, pela Tabela 10, que o setor que mais se reestruturou foi o de serviços. Em ambas as mesorregiões analisadas, esse setor apresentou grandes mudanças na hierarquia das atividades que mais participavam da concentração de mão de obra. Em segundo e terceiro lugares, com mais mudanças, ficaram os setores da agropecuária e da indústria, respectivamente, em ambas as mesorregiões. Essas informações mostram que houve uma diversificação setorial ao longo do tempo nesses dois setores, corroborando os resultados dos demais indicadores analisados neste artigo.

\section{Considerações Finais}

O escopo deste artigo foi analisar os determinantes dos desempenho econômico global e setorial de mesorregiões selecionadas do Brasil Meridional, quais sejam: as mesorregiões Oeste Catarinense e Oeste Paranaense, no período 1970-2000. 
Conforme mostraram os resultados no modelo estrutural-diferencial, verificou-se que, a despeito da similaridade de suas estruturas originais, ao longo do tempo essas duas mesorregiões se especializaram em segmentos e setores produtivos distintos, que apresentaram dinamismos distintos, e essas diferenças de dinamismo nos setores motrizes das economias regionais consideradas estão na base da dinâmica global distinta dessas mesorregiões. E isso, fundamentalmente, porque os efeitos de encadeamento dos setores motrizes dessas mesorregiões foram diferenciados. O Oeste Paranaense e o Oeste Catarinense, que tinham, em 1970, uma produção agropecuária mais diversificada, com uma participação expressiva da pecuária de pequenos animais, aprofundaram esse perfil peculiar de especialização no período analisado, cujos efeitos se imporão no desempenho dos setores secundário e terciário.

As indústrias de produtos alimentares foram as que mais se destacaram, em geração de emprego no Oeste Catarinense, seguidas da construção civil. No Oeste Paranaense esses dois setores também foram representativos, mas a construção civil estava na primeira colocação. De outro lado, apesar do Oeste Paranaense ter aprofundado a especialização na cultura da soja, ele não aprofundou apenas sua dedicação à soja, mas também à pecuária suína e avícola, diversificando sua agropecuária. No Oeste Catarinense, a agroindustrialização da pecuária de pequenos e médios animais, bem como a diversificação da agropecuária, também foram o carro-chefe dos seus dinamismos.

Assim essas duas mesorregiões apresentaram um desempenho setorial e global favorável. O Oeste Paranaense ficou em melhores posições, principalmente quando se analisa o setor terciário. A diversificação produtiva, confirmada pelo coeficiente de reestruturação, existente nessas mesorregiões contribuiu, e muito, para esses comportamentos positivos. Assim, a diversificação e multiespecialização produtivas devem ser objetivos que as regiões devem buscar durante o seu processo de desenvolvimento.

Enfim, as opções produtivas dessas mesorregiões, principalmente do setor agropecuário, que, no ano de 2000, eram suínos, aves e milho, no Oeste Catarinense, e soja, aves, milho e suínos, no Oeste Paranaense, e a indução de economias externas (caracterizadas principalmente pelas indústrias de produtos alimentares nessas mesorregiões), e dos efeitos de encadeamentos nos três macrossetores, foram as principais explicações do desempenho econômico mesorregional. Assim, no período 1970-2000, houve uma melhor diversificação e integração dos macrossetores do Oeste Catarinense e Oeste Paranaense. Portanto, esse artigo reforça a ideia de que quanto mais diversificada (multiespecializada) for uma região, melhor será o resultado do desenvolvimento para toda a economia, e as autarquias, em todas as suas esferas, devem trabalhar nesse sentido.

\section{Referências}

BERNARDES, N. Bases geográficas do povoamento do estado do Rio Grande do Sul. Ijuí: Editora da Unijuí, 1997.

ALVES, L. R.; PAIVA, C. A. N. Determinantes do desempenho econômico das mesorregiões... 
BRUM, A. J. Modernização da agricultura: trigo e soja. Petrópolis: Vozes, 1988.

CORREAA, R. L. Trajetórias geográficas. Rio de Janeiro: Bertrand Brasil, 1997.

ESPÍNDOLA, C. J. As agroindústrias no Brasil: o caso da Sadia. Chapecó: Grifos, 1999.

HADDAD, P. R. (Org.). Economia regional: teoria e métodos de análise. Fortaleza: BNB/ETIENE, 1989.

. Padrões regionais de crescimento do emprego industrial de 1950 a 1970. Revista Brasileira de Geografia, Rio de Janeiro, v. 39, n. 1, p. 3-45, jan./mar. 1977.

HARVEY, D. Condição pós-moderna. São Paulo: Edições Loyola, 1994.

HILHORST, J. G. M. Planejamento regional: enfoque sobre sistemas. 2 ed. Rio de Janeiro: Zahar, 1975.

HIRSCHMAN, A. Estratégia do desenvolvimento econômico. Rio de Janeiro: Fundo de Cultura Econômica, 1961.

INSTITUTO BRASILEIRO DE GEOGRAFIA E ESTATÍSTICA. Banco de dados agregados - SIDRA. Disponível em: <http://www.ibge.gov.br> Acesso em: 15 ago. 2006.

. Censo demográfico 1970: microdados, Paraná - Santa Catarina - Rio Grande dos Sul; questionário da amostra. Rio de Janeiro: IBGE, 2005. 1 CDROM

. Censo demográfico 2000: microdados, Paraná - Santa Catarina - Rio Grande dos Sul; questionário da amostra. 2. ed. Rio de Janeiro: IBGE, 2002. 1 CDROM

. Censo agropecuário: Rio Grande do Sul. Rio de Janeiro: IBGE, 1974a. (VIII Recenseamento Geral - 1970, Série Nacional, v. III, Tomo XXI).

. Censo agropecuário: Paraná. Rio de Janeiro: IBGE, 1974b. (VIII Recenseamento Geral 1970, Série Regional, v. III, Tomo XIX).

. Censo agropecuário: Santa Catarina. Rio de Janeiro: IBGE, 1974c. (VIII Recenseamento Geral - 1970, Série Regional, v. III, Tomo XX).

IPEADATA. Dados macroeconômicos e regionais. Disponível em: < http://www.ipeadata.gov.br > Acesso em: 15 mar. 2009.

INSTITUTO DE PESQUISA ECONÔMICA APLICADA. Caracterização e tendências da rede urbana do Brasil: redes urbanas regionais - Sul. Brasília: IPEA, 2000.

LAGEMANN, E. Formação sócio-econômica da região Sul do Brasil. Estudos do CEPE, Santa Cruz do Sul, n. 7/8, p. 105-143, jan./dez. 1998.

LODDER, C. A. Padrões locacionais e desenvolvimento regional. Revista Brasileira de Economia, v. 28, n. 1, p. 3-128, jan./mar. 1974. 
MOREIRA, R. A nova divisão territorial do trabalho e as tendências de configuração do espaço brasileiro. In: LIMONAD, E.; HAESBAERT, R.; MOREIRA, R. (Org.). Brasil século XXI por uma nova regionalização: agentes, processos e escalas. São Paulo: Max Lomonad, 2004. p. 123-152.

NORTH, D. C. Teoria da localização e crescimento econômico regional. In: SCHWARTZMAN, Jacques (Org.). Economia regional: textos escolhidos. Belo Horizonte: CEDEPLAR, 1977 .

. A agricultura no crescimento econômico regional. In: SCHWARTZMAN, Jacques

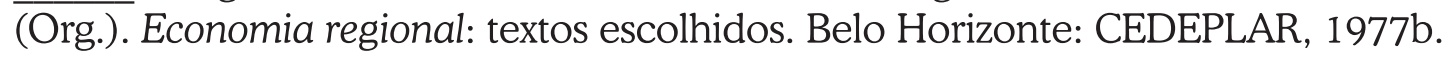

. The economic growth of the United States 1790-1860. Washington-USA: Prentice-Hall, 1961a.

. Alguns problemas teóricos a respeito do crescimento econômico regional. Revista Brasileira de Economia, n. 3, p. 25-38, set. 1961b.

PADIS, P. C. Formação de uma economia periférica: o caso paranaense. 2 ed. Curitiba: IPARDES, 2006.

PAIVA, C. A. N. Desenvolvimento regional, especialização e suas medidas. Indicadores Econômicos. Porto Alegre: FEE, v. 34, n. 1. jan./mar. 2006.

. Demanda Efetiva, Exportações e Desenvolvimento Regional. (ou: Smith, Kalecki e

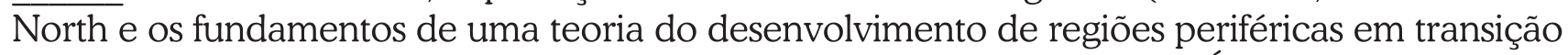
para o capitalismo). In: IX ENCONTRO NACIONAL DE ECONOMIA POLÍTICA. Anais...

Sociedade Brasileira de Economia Política, Uberlândia (MG), jun. 2004.

SANTOS, M. A natureza do espaço: técnica e tempo, razão e emoção. São Paulo: Hucitec, 1996.

SILVA, J. C. C. A análise de componentes de variação (shift-share). In: COSTA, José Silva.

Compêndio de economia regional. Coimbra, Portugal: APDR, 2002.

\section{Apêndice A - Método Estrutural-Diferencial (Shift And Sharel e Coeficiente de Reestruturação Setorial}

Em primeiro lugar devem-se considerar as seguintes definições:

$P O_{i j}=$ Pessoas Ocupadas, ou o VBPA, no setor $i$ da mesorregião j;

$P O_{i j}=$ Total de Pessoas Ocupadas, ou o VBPA total, na mesorregião j;

$P O_{i t}=$ Pessoas Ocupadas, ou o VBPA, do setor $i$ no Sul do Brasil;

$P O_{t t}=$ Total de Pessoas Ocupadas, ou o VBPA total, no Sul do Brasil.

O método estrutural-diferencial de análise do crescimento econômico regional é tradicionalmente conhecido como modelo shift and share. Esse método divide a variação (crescimento) na produção (ou no produto, ou no 
emprego etc) de uma determinada atividade em três componentes: componente nacional ou macrorregional, componente setorial ou proporcional e componente diferencial ou regional, conforme apresentam Haddad (1977), Haddad (1989), Lodder (1974) e Silva (2002).

A componente (ou variação) macrorregional $(R)$ é quanto teria variado o valor da produção no setor " $x$ " qualquer se o mesmo tivesse crescido à taxa média do macrossetor de referência (que pode ser toda a economia, ou a agropecuária, ou a indústria, ou os serviços) na macrorregião de referência. A equação 2 apresenta sua forma de cálculo.

$$
R=\sum_{i} P O_{i j}^{T 0}\left(r_{t t}-1\right)
$$

Onde

$$
r_{t t}=P O_{t t}^{T 1} / P O_{t t}^{T 0}
$$

O componente setorial, ou proporcional $(\mathrm{P})$, é a diferença entre a variação do setor específico (por exemplo: o setor soja vis-à-vis a agropecuária como um todo; ou o setor agropecuária vis-à-vis a economia como um todo) na macrorregião de referência e a variação agregada da mesma macrorregião, multiplicada pela produção (ou seu índice) em cada setor na mesorregião sob análise no início do período. O somatório dessas diferenças vai esclarecer se a estrutura produtiva inicial da mesorregião sob análise sobre o desempenho da economia - vale dizer: se sua especialização setorial inicial - favoreceu (valores positivos) ou prejudicou (valores negativos) o desempenho de sua economia.

$$
P=\sum_{i} P O_{i j}^{T 0}\left(r_{i t}-r_{t t}\right)
$$

Onde

$$
r_{i t}=\sum_{j} P O_{i j}^{T 1} / \sum_{j} P O_{i j}^{T 0}
$$

Finalmente, o componente diferencial (D) nos informa a diferença entre a taxa de variação efetiva de cada setor em cada mesorregião e a variação que a região teria obtido se o setor tivesse apresentado na mesorregião o mesmo desempenho que apresentou na macrorregião de referência. Ela informa se a mesorregião cresceu mais (ou menos) do que a média da macrorregião de referência em cada setor, indicando se a mesorregião tem vantagens (ou desvantagens) competitivas (ou diferenciais) em cada setor. A soma dos componentes diferenciais setoriais nos informa se a mesorregião apresentou uma performance superior ou inferior à macrorregião de referência nos distintos macrossetores (agricultura, indústria e serviços). 


$$
D=\sum_{i} P O_{i j}^{T 0}\left(r_{i j}-r_{i t}\right)
$$

Onde

$$
r_{i j}=P O_{i j}^{T 1} / P O_{i j}^{T 0}
$$

Assim, os resultados desse modelo identificarão os setores mais (menos) dinâmicos durante esse período.

Já, o coeficiente de reestruturação $(\mathrm{Cr})$ é apresentado pela equação 4 e objetiva avaliar o grau de mudança na especialização da mesorregião.

$$
C r=\frac{\sum_{i}\left|\left(P O_{i j} / \sum_{i} P O_{i j}\right)-\left(P O_{i j} / \sum_{i} P O_{i j}\right)\right|}{2}
$$

$\mathrm{O} \mathrm{Cr}$ relaciona a estrutura do emprego por mesorregião entre dois períodos, ano base 0 e ano 1, objetivando verificar o grau de mudanças na especialização das mesorregiões em análise. Coeficientes iguais a zero indicam que não ocorreram modificações na estrutura setorial da mesorregião e iguais, ou próximos, a um demonstram uma reestruturação bem substancial.

Recebido em: 14/07/2009.

Aceito em: 23/12/2010. 